\title{
AKAP9, a Regulator of Microtubule Dynamics, Contributes to Blood-Testis Barrier Function
}

\author{
Deepak Venkatesh, ${ }^{*}$ Dolores Mruk, ${ }^{\dagger}$ Jan M. Herter, ${ }^{*}$ Xavier Cullere, ${ }^{*}$ Katarzyna Chojnacka, ${ }^{\dagger}$ C. Yan Cheng, ${ }^{\dagger}$ and \\ Tanya N. Mayadas*
}

From the Center for Excellence in Vascular Biology,* Department of Pathology, Brigham and Women's Hospital and Harvard Medical School, Boston, Massachusetts; and the Mary M. Wohlford Laboratory for Male Contraceptive Research ${ }^{\dagger}$ Center for Biomedical Research, Population Council, New York, New York

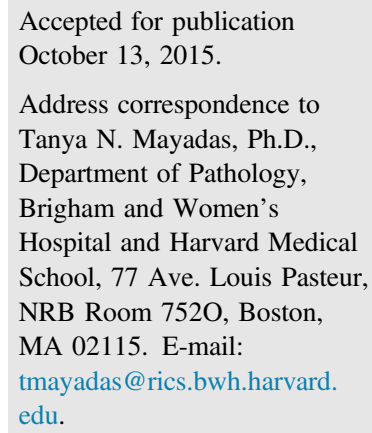

\begin{abstract}
The blood-testis barrier (BTB), formed between adjacent Sertoli cells, undergoes extensive remodeling to facilitate the transport of preleptotene spermatocytes across the barrier from the basal to apical compartments of the seminiferous tubules for further development and maturation into spermatozoa. The actin cytoskeleton serves unique structural and supporting roles in this process, but little is known about the role of microtubules and their regulators during BTB restructuring. The large isoform of the cAMP-responsive scaffold protein AKAP9 regulates microtubule dynamics and nucleation at the Golgi. We found that conditional deletion of Akap9 in mice after the initial formation of the BTB at puberty leads to infertility. Akap 9 deletion results in marked alterations in the organization of microtubules in Sertoli cells and a loss of barrier integrity despite a relatively intact, albeit more apically localized F-actin and BTB tight junctional proteins. These changes are accompanied by a loss of haploid spermatids due to impeded meiosis. The barrier, however, progressively reseals in older Akap 9 null mice, which correlates with a reduction in germ cell apoptosis and a greater incidence of meiosis. However, spermiogenesis remains defective, suggesting additional roles for AKAP9 in this process. Together, our data suggest that AKAP9 and, by inference, the regulation of the microtubule network are critical for BTB function and subsequent germ cell development during spermatogenesis. (Am J Pathol 2016, 186: 270-284; http://dx.doi.org/10.1016/j.ajpath.2015.10.007)
\end{abstract}

The blood-testis barrier (BTB), one of the tightest blood-tissue barriers in mammals, creates a unique microenvironment for the development and maturation of germ cells. The BTB, found between adjacent Sertoli cells near the basement membrane of the seminiferous epithelium of the testis, anatomically divides the epithelium into the basal and apical compartment. It is composed of intermediate filament-based desmosomes and coexisting actin-based tight junctions (TJs), basal ectoplasmic specialization (ES; a testis-specific atypical adherens junction), and gap junctions (GJs). ${ }^{1}$ The BTB assembles at puberty and thereafter undergoes extensive assembly and disassembly to allow preleptotene spermatocytes in the basal compartment to be transported to the apical compartment for further development. Thus, germ cell transport is associated with exquisite coordination of the Sertoli cell cytoskeleton. There is emerging evidence that cyclic BTB restructuring relies on the F-actin cytoskeleton, a prominent ultrastructural feature of the BTB, which facilitates endocytic vesicle-mediated cell adhesion functions at the basal ES. ${ }^{1}$ However, little is known about the role and regulation of the microtubule (MT) network in BTB dynamics and spermatogenesis., ${ }^{2,3}$

Signal-organizing scaffolding proteins, called AKAPs, compartmentalize and ensure specificity of cAMP-signaling networks. ${ }^{4}$ AKAPs localize to discrete cell compartments and bind protein kinase A (PKA) and in some cases the cAMP-responsive guanine exchange factor Epac1 to spatially restrict the activity of these proteins toward a subset of effector molecules. ${ }^{5,6}$ AKAP9, also known as

Supported by NIH grants PO1 HL 036028 (T.N.M.) and RO1 HD056034 (C.Y.C.).

D.M. and J.M.H. contributed equally to this work.

Disclosures: None declared. 
AKAP450 or CG-NAP, is a 450-kDa protein that binds both $\mathrm{PKA}^{4}$ and Epac1. ${ }^{7}$ The shorter $220-\mathrm{kDa}$ isoform Yotiao is present in the cytosol. The plasma membrane anchors the $N$-methyl-D-aspartic acid (NMDA) receptor in the brain ${ }^{8}$ and regulates the $\mathrm{K}^{+}$channel subunit KCNQ1 in the heart, which may account for the occurrence of long-QT syndrome, a heritable cardiac arrhythmia syndrome in patients with Yotiao mutations. ${ }^{9}$ The longer isoform AKAP450 localizes to the centrosome and Golgi, confers MT-nucleating activity at the Golgi, ${ }^{10}$ and regulates MT dynamics. $^{7,11}$ MTs are dynamic asymmetric structures that transition between growing and shrinking phases at their plus ends. Their stabilization, via capture of their growing ends, defines a polarity axis in cells for transport and targeted delivery of vesicles and protein complexes. MT plus end-binding proteins, such as EB1, are key regulators of MT plus end dynamics. ${ }^{12}$ In endothelial cells, AKAP9 silencing leads to a decrease in EB1 comets at the tips of MTs that is associated with a reduction in the MT polymerization rate and MT growth stimulated by Epac1/2. ${ }^{7}$ AKAP 9 silencing prevents Epac-induced increases in endothelial barrier function, ${ }^{7}$ reduces epithelial cell-directed migration ${ }^{10}$ and barrier function, ${ }^{13}$ and alters immune synapse formation during T-cell antigen recognition. ${ }^{14}$ In vivo, a recent study found that an Akap9 null mutant (Akap $9^{\text {mei2. } .5 / m e i 2.5}$, with a stop codon after exon 14) generated by random chemical mutagenesis and Akap9-deficient male mice with a deletion of exon 8 were infertile. Physiologic and morphologic

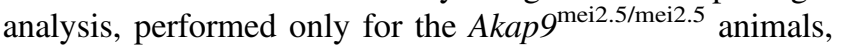
attributed the infertility to a defect in Sertoli cell maturation. ${ }^{15}$

To delineate the role of AKAP9 and its MT-regulating activity in BTB function, we generated mice with conditional and inducible Akap9 deletion for spatiotemporal restriction of Akap9 deficiency and mice with global Akap9 deletion. The BTB, established at postnatal day 15 in mice, ${ }^{16}$ separates the mitotic/spermatogonial and meiotic/ spermatocyte compartment and undergoes remodeling at stage VIII of the seminiferous epithelial cell cycle to facilitate the transport of preleptotene spermatocytes across the barrier so that meiosis I/II and subsequent postmeiotic spermatid development can take place in the adluminal compartment behind the BTB. ${ }^{1}$ We exploited the VEcadherin promoter for a conditional Cre recombinase deletion of Akap9 in the testes because in addition to its well known expression in endothelial cells, ${ }^{17}$ VE-cadherin exhibits epithelial cycle stage-specific expression in the Sertoli cells ${ }^{18,19}$ and in differentiating spermatids at stage II and elongated spermatids of mouse testes. ${ }^{19}$ Conditional or global Akap 9 deletion led to male infertility that could not be ascribed to a primary defect in spermatogenic cells or Sertoli cell maturation. Instead, we found that AKAP9 was necessary for organized MT structures in Sertoli cells and was required for cyclic BTB remodeling necessary for germ cell development and subsequent spermiogenesis.

\section{Materials and Methods}

\section{Generation of Global and Conditional AKAP9-Deficient Mice}

The gene-targeting construct obtained through European Conditional Mouse Mutagenesis program was introduced into C57Bl/6N embryonic stem (ES) cells, and cells were selected with G418 (Brigham and Women's Hospital Transgenic Core Facility, Boston, MA) and introduced into C57B1/6 blastocysts. Chimeric male mice were bred with $\mathrm{C} 57 \mathrm{~B} 1 / 6 \mathrm{~N}$ females to generate $A k a p 9^{\mathrm{t} / /+}$ mice. Heterozygous offspring were bred to $\mathrm{C} 57 \mathrm{Bl} / 6 \mathrm{~J}$ mice expressing eCAG-flp (CAG promoter driving $f l p$ recombinase) transgene ${ }^{20}$ (gift of Dr. Shigeyoshi Itohara, RIKEN Institute, Saitama, Japan) for recombination of frt sites, and VE-cadherin:tetracycline-regulated transactivator (tTA)/C57Bl/ $6{ }^{21}$ and tet-O-cre/C57B1/6 mice (The Jackson Laboratory, Bar Harbor, ME) for Cre recombination. Thus, all mutant and wild-type (WT) counterparts were generated on a C57Bl/6 strain.

AKAP9 genotyping was done in three reactions as depicted in Supplemental Figure S1: primer pair set 1, 5'-CCAGTTGGGCTCCGCAAAGGA-3' (forward) and $5^{\prime}$-AGTCTTCATCCAGATGCCCGACCT-3' (reverse); primer pair set 2, $5^{\prime}$-TGAAAATCCAGTTGGGCTCC-3' (forward) and $5^{\prime}$-TCGTGGTATCGTTATGCGCC-3' (reverse); primer pair set 3, $5^{\prime}$-GGGCTCCGCAAAGGAAAACGGT-3' (forward) and 5'-GCCCCAGACAGATGAACTGATGGC-3' (reverse). primers for VE-cadh-tTA were $5^{\prime}$-GACGCCTTAGCCATTGAGAT- $3^{\prime}$ (forward) and 5'-CAGTAGTAGGTGTTTCCCTTTCTT- $3^{\prime}$ (reverse), and for tet-O-Cre were $5^{\prime}$-GCGGTCTGGCAGTAAAAACTATC- $3^{\prime}$ (forward) and $5^{\prime}$-GTGAAACAGCATTGCTGTCACTT-3' (reverse).

Mice referred to as WT in our studies were heterozygous for the conditional allele or homozygous but lacking VEcadherin tTA or tet-O-Cre. All WT mice were age matched with $A k a p 9^{K O}$ or $A k a p 9^{c k o}$ animals. For inducible deletion, Akap $9^{\text {cko }}$ breeding pairs were given grain-based doxycycline $(200=\mathrm{mg} / \mathrm{kg}$ pellets, sterile), and resulting offspring continued to receive doxycycline until postnatal day 30 , weeks after which the mice were weaned and given a normal chow diet.

The Institutional Animal Care and Use Committee at Harvard Medical School approved all protocols concerning animal use. Mice were maintained in a pathogen-free facility with standard light/dark cycling and access to food and water ad libitum. Euthanasia was performed by carbon dioxide inhalation followed by cervical dislocation. Mice subjected to intravital microscopy (IVM) were anesthetized with ketamine and xylazine.

\section{Western Blot Analysis}

Whole testes were homogenized in radioimmunoprecipitation assay buffer with protease and phosphatase inhibitors and centrifuged to remove debris and boiled in Laemmli buffer. Isolated Sertoli cells and germ cells were boiled in Laemmli 
buffer. Total protein estimates in each sample were determined using the Pierce BCA Protein Assay Reagent A (ThermoFisher Scientific, Waltham, MA). Samples were resolved by SDS-PAGE and transferred to nitrocellulose membranes (Bio-Rad, Hercules, CA) and processed for Western blot analysis using rabbit anti-Cre recombinase antibody (Cell Signaling Technology, Danvers, MA) and a 24 antiAKAP9 antibody directed against exons 24 to $27^{22}$ (a gift from Dr. Michel Bornens, CNRS-Institut CURIE, Paris, France).

\section{DNA Content Analysis}

Testes were excised from mice, dissociated into single cells, and filtered through cell strainers. Testicular cells were fixed in $10 \%$ formalin solution (Sigma-Aldrich, St Louis, MO), permeabilized $[0.5 \%$ Triton X-100 in phosphate-buffered saline (PBS)], treated with $1 \mu \mathrm{g} / \mathrm{mL}$ of RNase A (SigmaAldrich), and stained with $50 \mu \mathrm{g} / \mathrm{mL}$ of propidium iodide (Sigma-Aldrich). DNA content was analyzed by flow cytometry (BD FACS Calibur; Becton, Dickson and Company, Franklin Lakes, NJ) as previously described. ${ }^{23}$

\section{Histologic Analysis and Evaluation}

Testes were fixed overnight with Bouin's fixative at $4^{\circ} \mathrm{C}$, gradually dehydrated in ethanol, cleared with HistoClear, and paraffin embedded. Sections were cut at $5 \mu \mathrm{m}$ and stained with hematoxylin and eosin. Terminal deoxynucleotidyl transferase-mediated dUTP nick-end labeling was performed on 5- $\mu \mathrm{m}$ sections as per the manufacturer's protocol (TACS-XL In Situ Apoptosis Detection Kit; R\&D Systems, Minneapolis, MN).

\section{Immunofluorescence and IHC}

\section{Immunofluorescence}

Frozen testis sections (snap frozen in OCT followed by generation of $5-\mu \mathrm{m}$ sections) were incubated with blocking buffer (5\% goat serum, $2 \%$ bovine serum albumin in PBS) followed by incubation at $4{ }^{\circ} \mathrm{C}$ with the following primary antibodies: JAM-A (Invitrogen, Carlsbad, CA), peanut agglutinin (PNAG), SYCP3, $\gamma$-H2AX, Kip1, and TRA98 (Abcam, Cambridge, MA), Gata1 (Cell Signaling Technology), ZO-1 (Invitrogen), and JAM-C (H36) (a gift from Dr. Michel Aurrand-Lions, Inserm, Marseille, France). Cultured mouse Sertoli cells were fixed in ice-cold methanol and acetone (1:1) for 2 minutes, blocking buffer as described above, and antibody to EB1 (Absea, Beijing, China). All samples were washed with PBS and incubated with Alex fluor-conjugated goat anti-rabbit secondary antibody (Invitrogen) and mounted in FluorSave. For filamentous actin staining, frozen sections were fixed in $4 \%$ paraformaldehyde in PBS, permeabilized in $0.1 \%$ Triton X-100 in PBS, and blocked with $1 \%$ bovine serum albumin in PBS. Sections were incubated with fluorescein isothiocyanate (FITC)conjugated phalloidin (Sigma-Aldrich) for 30 minutes and then mounted in ProLong Gold anti-fade reagent with DAPI (Invitrogen).

IHC

Immunohistochemistry (IHC) was performed using Bouin or $5-\mu \mathrm{m}$ formalin-fixed, paraffin-embedded sections as described. ${ }^{24}$ Sections were deparaffinized, rehydrated, and subjected to antigen retrieval using $10 \mathrm{mmol} / \mathrm{L}$ citrate buffer $\left(\mathrm{pH} 6.0\right.$ at $22^{\circ} \mathrm{C}$ ) for 10 minutes in a microwave. Sections were blocked with $10 \%$ normal rabbit serum and then incubated with primary antibody against $\beta$-tubulin (Abcam), EB1 (Santa Cruz Biotechnology, Santa Cruz, CA), connexin-43, and Cre recombinase (Cell Signaling Technology) overnight at $4^{\circ} \mathrm{C}$ as described previously. ${ }^{24}$ Thereafter, sections were incubated with the respective biotinylated IgG followed by streptavidin-horseradish peroxidase (Invitrogen) and aminoethyl carbazole (Invitrogen) as the substrate.

\section{Sertoli and Germ Cell Isolation}

Primary Sertoli cells were isolated from testes of 60-day-old mice and cultured in serum-free F12/Dulbecco's modified Eagle's medium supplemented with growth factors and bacitracin as described, ${ }^{25}$ and modified and detailed elsewhere. ${ }^{26}$ To harvest germ cells and Sertoli cells from the same sample, testes from day 90 mice were sequentially enzymatically treated and mechanically disrupted as described. ${ }^{26}$ Next, we recovered germ cells from the supernatant and Sertoli cell aggregates from the pellet after a low-centrifuge spin. The germ cells were filtered through glass wool to remove elongated spermatids. ${ }^{27}$ An aliquot of cell suspensions of the two populations were deposited onto glass slides using a cytocentrifuge and stained with Giemsa.

\section{Analysis of BTB Integrity by IVM and the Biotin Tracer Method}

Mice received $1 \mathrm{mg} / \mathrm{kg}$ of Hoechst 33,342 via tail vein injection. After 30 minutes, mice were anesthetized with i.p. injections of ketamine and xylazine and were placed on a heating pad to maintain body temperature. After cannulation of the left carotid artery, $1 \mathrm{mg} / \mathrm{kg}$ of $2-\mathrm{MDa}$ TRITC Dextran (Life Technologies, Grand Island, NY) in PBS was injected. The left testis was then exteriorized as described previously ${ }^{28}$ except the cremaster was removed and the testis was fixed on a custom-built stage and surrounded by gauze soaked in warm PBS, and a coverslip was applied gently. Multiphoton microscopy was performed on a Prairie Technologies Ultima Two Photon Microscope using a Tsunami Ti:sapphire laser with a 10-W MilleniaXs pump laser (Spectra-Physics, Santa Clara, CA). Once the testis was immobilized, $200 \mu \mathrm{L}$ of $10 \mathrm{mg} / \mathrm{mL}$ FITC-inulin was injected into the carotid artery, and 50- to $100-\mu \mathrm{m}$ optical stacks located 5 to $20 \mu \mathrm{m}$ below the capsule of the testes were acquired every 
2.5 minutes for 1.5 hours with $10-\mu \mathrm{m}$ spacing using a $20 \times$ objective (numerical aperture, 0.95). Images were then reconstructed and analyzed using ImageJ version $1.48 \mathrm{v}$ (NIH, Bethesda, MD; http://imagej.nih.gov/ij). ${ }^{29}$ The biotin tracer studies were performed as previously described. ${ }^{30}$ Briefly, the testes of anesthetized mice were exteriorized, and EZ-Link Sulfo-NHS-LC-Biotin (ThermoFisher Scientific) was injected into the interstitial space using a 30 -gauge needle. After 30 minutes, animals were euthanized and the testes removed and fixed in cold neutral buffered formalin and then processed for paraffin embedding. The slides were deparaffinized, rehydrated, and incubated with Alexa Fluor 488-linked streptavidin (Invitrogen), rinsed with PBS, and mounted with medium that contained DAPI. For quantification, a region of interest was drawn, and intratubular mean fluorescence intensity within this region was measured using ImageJ software.

\section{Statistical Analysis}

Analysis of variance for repeated measurements was performed for timeline experiments (SPSS version 22; SPSS Inc, Chicago, IL) and paired $t$-test for all other data. $P<0.05$ was considered statistically significant.

\section{Results}

\section{Generation of Mice with Global Akap9 Deletion and Conditional Deletion at Puberty}

Mice were generated with a conditional targeted Akap9 allele $\left(\operatorname{Akap} 9^{\mathrm{f} / \mathrm{fl}}\right)$ in which loxP sites flanked exon 8. Our strategy was to generate mice with a conditional deletion of $A k a p 9$ in the testes at puberty $\left(A k a p 9^{\text {cko }}\right)$ to assess the potential role of AKAP9 in the function of Sertoli cells after their maturation and initial formation of the BTB. For this, $A k a p 9^{\mathrm{fl} / \mathrm{fl}}$ mice were bred to transgenic mice expressing $t T A$ driven by the VE-cadherin promoter (VE-cad-tTA) and Cre recombinase under the control of a tetracycline-responsive promoter element (tetO-Cre) (Supplemental Figure S1A). Success of this strategy relies on the epithelial cycle stage-specific expression of VE-cadherin, and therefore its promoter activity, in the mouse testes. ${ }^{19}$ VE-cadherin expresses exclusively in postmeiotic haploid step 14 to 16 spermatids at stages II to VII, which predicts that Akap9 deletion occurs in late-stage germ cells during each epithelial cell cycle. On the other hand, VE-cadherin expression in Sertoli cells at stage VIII, ${ }^{19}$ when extensive BTB remodeling is initiated, predicts permanent deletion of AKAP9 in this cell population because Sertoli cells terminally differentiate and cease to turnover at this stage. To directly assess Cre recombinase expression in VE-cad-tTA/tetO-Cre mice $\left(\mathrm{WT}^{\mathrm{VE}-\mathrm{Cad} / \mathrm{Cre}}\right.$ ), we conducted IHC of the testes and Western blot analysis of germ cells and Sertoli cells isolated from the same animal using an antibody that detects Cre recombinase.
Testes from age-matched WT mice lacking the tetO-Cre transgene served as a negative control (Figure 1, A and B). Cre recombinase was present in the elongated spermatids of testes cross sections of $\mathrm{WT}^{\mathrm{VE}-\mathrm{Cad} / \mathrm{Cre}}$ mice; however, the observed staining of spermatogonia in these samples was nonspecific because it was also detected in sections from WT mice that lack tetO-Cre (Figure 1A). A similar staining pattern was obtained with an independent Cre recombinase antibody, and no staining was observed with secondary antibody alone (data not shown). Western blot analysis of separated Sertoli and germ cell populations revealed a specific band for Cre recombinase in Sertoli cells of $\mathrm{WT}^{\mathrm{VE}-\mathrm{Cad} / \mathrm{Cre}}$ that was absent in germ cells isolated from the same animal. This band was specific for Cre recombinase because it was absent in the Sertoli and germ cells of mice lacking tetO-Cre (WT) (Figure 1B). Together, our results indicate that VE-cadherin promoter drives Cre recombinase in spermatids and Sertoli cells but not in other germ cell populations.

Global Akap9 null mice $\left(A k a p 9^{\mathrm{KO}}\right)$ were generated by breeding Akap $9^{\text {cko/+ }}$ male mice, which takes advantage of VEcadherin promoter activity in germ cells ${ }^{19}$ and thus production of sperm that contain an Akap9-deleted allele. Akap9 gene disruption was confirmed in cells from these mice by PCR analysis and sequencing of the relevant PCR product. We observed the expected absence of exon 8 and a change in frame at the junction of exons 7 and 9 that gave rise to a premature stop codon (data not shown). Western blot analysis in brain and lung tissue with an antibody that maps to human $A K A P 9$ exons 24 to $27^{10}$ revealed a $450-\mathrm{kDa}$ species expected of fulllength protein in WTs that was absent in Akap $9^{\mathrm{KO}}$ tissue (Supplemental Figure S1B). Because the AKAP9 antibody recognizes the C-terminus, we cannot rule out the existence of shorter isoforms in Akap $9^{\mathrm{KO}}$ mice because available antibodies to the N-terminus of AKAP9 that were tested failed to react with mouse AKAP9 (data not shown). An additional, prominent smaller AKAP9 band is observed in WT but not in $A K A P 9^{\mathrm{KO}}$ samples (Supplemental Figure S1B), which may be another AKAP9 isoform apart from Yotiao because its molecular weight is greater than the expected 220-kDa Yotiao, or a degradation product of AKAP9.

Western blot analysis detected AKAP9 protein in testes harvested from postnatal day $60 \mathrm{WT}$ mice. This was absent or significantly reduced in $\operatorname{Akap} 9^{\mathrm{KO}}$ and $A k a p 9^{\mathrm{cko}}$ testes, respectively (Figure $1 \mathrm{C}$ ), with the remaining AKAP9 in the latter likely originating from peritubular myiod and Leydig cells. Analysis of AKAP9 in freshly isolated Sertoli cells revealed a prominent band for AKAP9 in WT cells that was absent in $A k a p 9^{\mathrm{KO}}$ and markedly reduced in Akap $9^{\text {cko }}$ samples (Figure 1C).

Impaired First Wave of Spermatogenesis in Conditional Akap9-Deficient Mice

Postnatal day $60 A k a p 9^{\text {cko }}$ and $A k a p 9^{\mathrm{KO}}$ males failed to produce mature spermatozoa and were infertile. Dissected testes of $\operatorname{Akap}^{\mathrm{cko}}$ (Figure 1D) and $\operatorname{Akap}^{\mathrm{KO}}$ (data not 

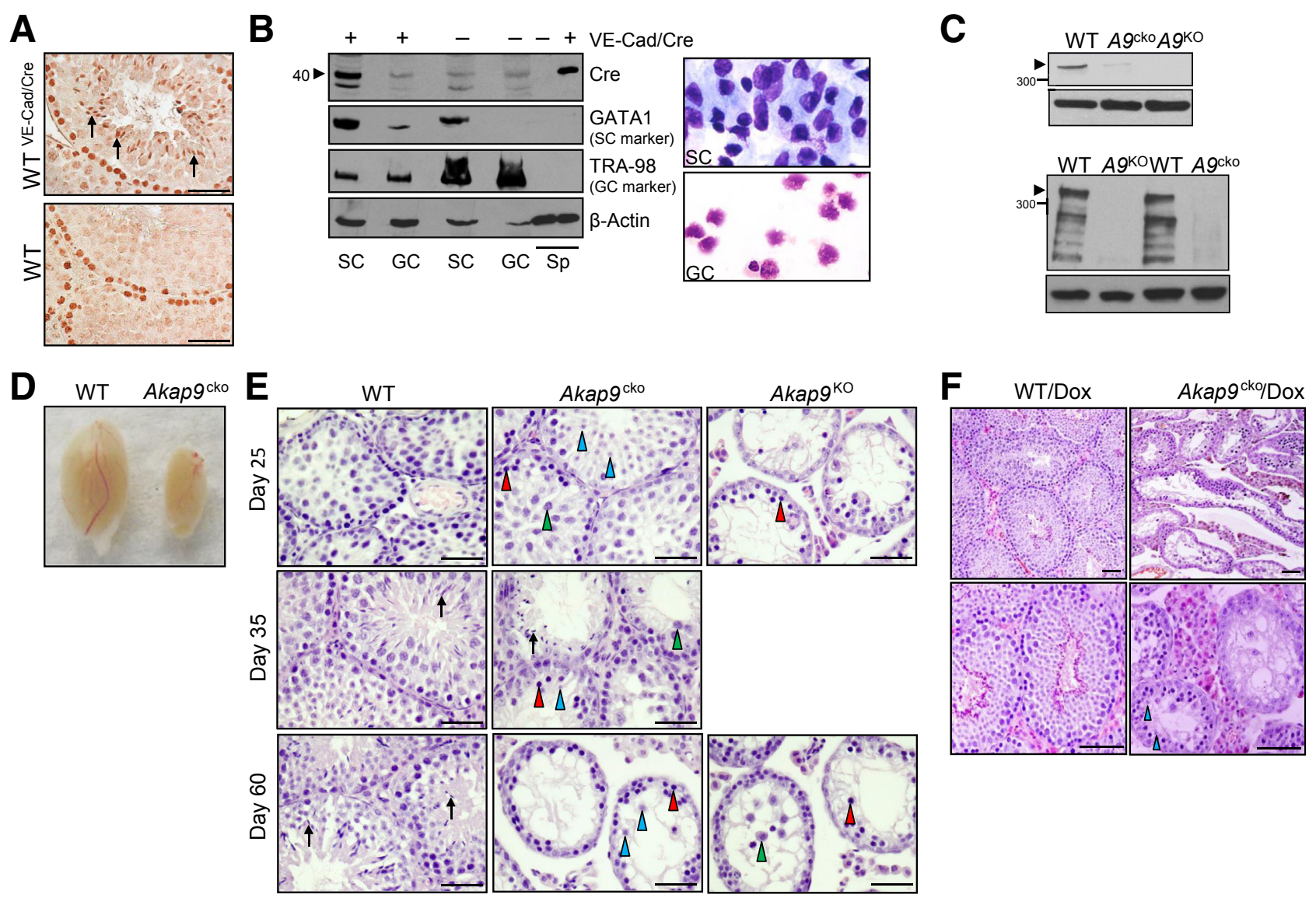

Figure 1 Conditional deletion of Akap9 in Sertoli cells (SCs) and germ cells (GCs) results in defects in spermatogenesis. A: Immunohistochemistry (IHC) of Cre expression in VE-cadherin (VE-Cad) tetracycline-regulated transactivator (tTA)/tet0-Cre and wild-type (WT) mice testes. Cross sections were subjected to IHC staining using antibody to Cre recombinase. Cre recombinase immunoreactivity was observed in elongated spermatids (arrows). Staining of spermatogonia was nonspecific because similar staining was observed in WT mice that do not have the tet0-Cre gene. B: Western blot analysis of Cre expression in GC and SC populations. Cell lysates of freshly isolated cells from postnatal day 90 VE-Cad-tTA/tet0-Cre and WT mice were subjected to Western blot analysis using anti-Cre recombinase antibody. Antibody for GATA1 and TRA98 served as markers for SCs and GCs, respectively. Actin served as a loading control. Spleen (Sp) samples from VE-Cad-tTA/tet-0-Cre and WT mice served as positive and negative controls, respectively. Cytospins of freshly isolated SCs and GCs were stained with Giemsa. C: Western blot analysis of AKAP9 expression in testes and Sertoli cells. Cell lysates of whole testes (top panel) and freshly isolated SCs (bottom panel) from postnatal day $60 \mathrm{WT}$, $A$ kap $9^{\mathrm{cko}}\left(A g^{\mathrm{cko}}\right)$, and $A k a p 9^{\mathrm{KO}}\left(A g^{\mathrm{KO}}\right)$ mice were subjected to Western blot analysis using anti-AKAP9 antibody. Actin served as a loading control. Arrowheads indicate the location of the AKAP9 long isoform. D: A representative image shows a significant reduction in the size of the $A_{k a p} 9^{\text {cko }}$ versus WT testes. E: Hematoxylin and eosin (H\&E)-stained cross sections of testes reveal severe defects in spermatogenesis in day 25 Akap $9^{\mathrm{KO}}$ mice, including the lack of round spermatids (blue arrowheads) despite the presence of leptotene SCs (red arrowheads), whereas in similarly aged Akap ${ }^{\text {cko }}$ mice, spermatogenesis appears normal. By day $35, A k a p 9^{\text {cko }}$ mice exhibit a complex phenotype in which meiosis was considerably disrupted because fewer round spermatids and pachytene SCs (green arrowheads) are detected, and elongating spermatids (black arrows) are only occasionally present. By day 60, Akap ${ }^{\text {cko }}$ mice resemble $A k a p g^{\mathrm{KO}}$ but have a few round spermatids in some tubules, suggesting meiosis is severely impeded but not arrested. However, there is no evidence of elongating/elongated spermatids, illustrating an arrest of spermiogenesis. F: Inducible Akap 9 deletion by doxycycline treatment and then removal result in spermatogenesis defects. Doxycycline (Dox) was given to breeding pairs and resulting offspring up to postnatal day 30 and then removed to allow Cre recombination. Testes from $A k a p g^{\mathrm{WT}} /$ Dox and $A k a p g^{\mathrm{cko}} /$ Dox animals were harvested at postnatal days 85 to 90 , and sections were stained with H\&E. Akap $9^{\mathrm{WT}} /$ Dox has the expected complement of germ cells and tubule architecture, whereas $A k a p 9^{\text {cko }} /$ Dox has a significant deficit in these parameters although few round spermatids are detected. $n=1$ representative of three independent experiments (A and B). Scale bars: $100 \mu \mathrm{m}(\mathbf{A}, \mathbf{E}$, and $\mathbf{F}$, bottom row); $50 \mu \mathrm{m}(\mathbf{F}$, top row).

shown) mice at 60 days post partum (dpp) were less than one-third the size of those of heterozygous mutant littermates, despite comparable body weights. The epididymis was also smaller in the $\operatorname{Akap} 9^{\text {cko }}$ mutants (Supplemental Figure S1C), but genitourinary organs were similar in size to heterozygote counterparts (data not shown). Histologic analysis of testes at postnatal days 25 to 60 was conducted to identify the extent of spermatogenesis affected by conditional or global Akap9 deficiency. At $25 \mathrm{dpp}$, testes of $\operatorname{Akap} 9^{\mathrm{KO}}$ had deteriorated tubules with decreased tubular and luminal width and a considerable reduction in the number of round spermatids compared with age-matched WT testes (Figure 1E). On the other hand, the testes of 25-dpp conditional Akap9-deficient mice $\left(\right.$ Akap $9^{\text {cko }}$ ) had relatively normal morphologic features, Sertoli cell architecture, and germ cell populations, which indicates largely preserved spermatogenesis in these animals (Figure 1E). Of interest, by $35 \mathrm{dpp}$, defects in spermatogenesis emerged in Akap $9^{\text {cko }}$ and, by $60 \mathrm{dpp}$, was analogous to 25- and 60-dpp Akap $9^{\mathrm{KO}}$ mice. The presence but marked reduction in round 
spermatids suggests that meiosis is considerably impeded but not arrested. Moreover, despite the presence of occasional round spermatids in Akap $9^{\text {cko }}$ testes at $60 \mathrm{dpp}$, elongating/elongated spermatids were completely absent in all tubules examined (Figure 1E), suggesting an additional role for AKAP9 in spermiogenesis.

Although the VE-cadherin promoter drives Cre activity at puberty, the expression of this Cre recombinase under the control of a tetracycline-responsive promoter element allowed us to more precisely and temporally regulate Akap9 deletion in the testes. For this, doxycycline was given to breeding pairs to suppress Cre activity and then removed in the postnatal period on day 30 to allow Cre-mediated recombination and thus Akap 9 deletion (Akap $9^{\text {cko }} /$ Dox). These mice, at day 85 to 90 , exhibited significant defects in spermatogenesis compared with WT counterparts treated with the same doxycycline regimen (WT/Dox) (Figure 1F). Moreover, consistent with the phenotype in $\operatorname{Akap} 9^{\mathrm{KO}}$ and $A k a p 9^{\text {cko }}$ mice, no elongating/ elongated spermatids were present in $\operatorname{Akap} 9^{\text {cko/Dox }}$ animals.

\section{Postpubertal Deletion of Akap9 Leads to Loss of Haploid Spermatids That Is Associated with Impaired Meiosis}

Further evidence of defective spermatogenesis in $\operatorname{Akap} 9^{\text {cko }}$ testes at $60 \mathrm{dpp}$ was provided by immunofluorescence staining of germ cells and Sertoli cells. In WT testes, TRA98positive germ cell nuclei, spermatogonial stem cells, mitotic spermatogonia, and cells in the prediplotene stages of meiosis were observed, and Gata1-positive Sertoli cell nuclei were detected near the basement membrane at the periphery of seminiferous tubules as reported. ${ }^{31}$ In contrast, few abnormally large TRA98-positive germ cells were visible in adult Akap $9^{\text {cko }}$ tubules (Figure 2A), and abundant Gatal-positive Sertoli cells were present. To quantitate the change in cell populations in $A k a p 9^{\text {cko }}$ mice, the DNA contents of testicular
A
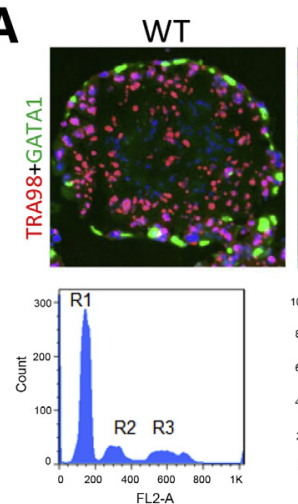

C
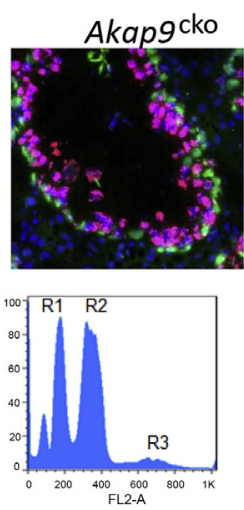
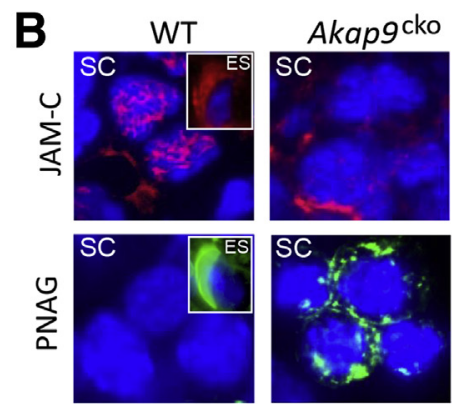
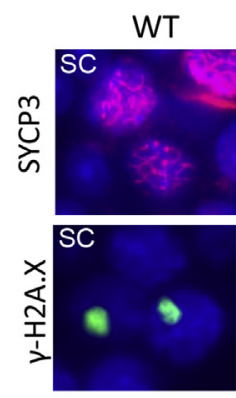

Akap9cko
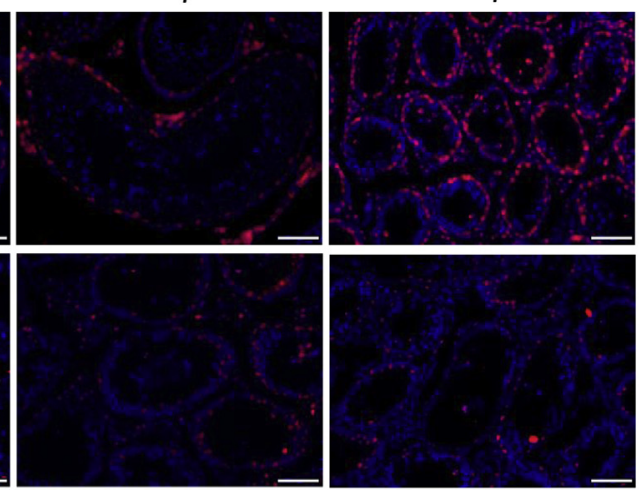

WT

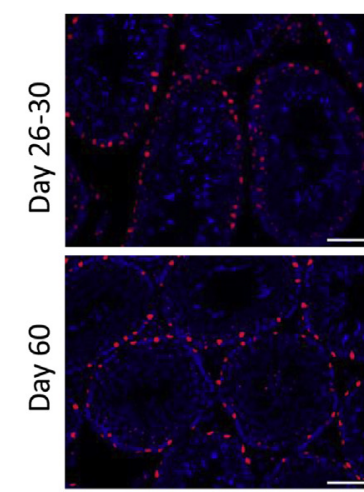

Figure 2 Akap9 deletion at puberty leads to defects in spermatogenesis despite normal Sertoli cell maturation. A: Examination of germ cell and Sertoli cell populations in wild-type (WT) and Akap ${ }^{\text {cko }}$ testes by immunofluorescence and FACS analysis. Cross section of seminiferous tubules immunostained for a nuclear marker of germ cells (TRA98, red/pink) and Sertoli cells (Gata1, green). FACS profiles after propidium iodide staining. R1: Round spermatid, elongated spermatid (ES), spermatozoa (1N); R2: spermatogonia, secondary spermatocytes (SC), somatic cells (2N); R3: primary SC (4N). B: Analysis of germ cell differentiation. Histologic cross sections were stained for junctional adhesion molecule-1 (JAM-C) and with peanut agglutinin (PNAG). Staining of SC and ES (insets, only in the case of WT samples). JAM-C concentrated in the anterior area of WT is reduced and mislocalized in Akap $9^{\text {cko }}$ SC. PNAG in WT is absent in SC and present in the acrosomal cap of ES, whereas in Akap $9^{\text {cko }}$ it is expressed in SC. Meiotic progress was evaluated by immunodetection of SYCP3 (red) and $\gamma-\mathrm{H} 2 \mathrm{AX}$ (green) and DAPI nuclear counterstain (blue). C: Cross sections of testes from the indicated mice and days stained with a negative cell cycle regulator $\mathrm{p} 27^{\mathrm{Kip} 1}$, a marker of Sertoli cell maturation. p2 $7^{\mathrm{Kip} 1}$ levels in Sertoli cells were comparable in testes of young (day 26 to 30 ) WT, Akapg $9^{\mathrm{cko}}$, and Akap $9^{\mathrm{KO}}$ mice, whereas in 60-day-old mice, a significant reduction in $227^{\mathrm{Kip} 1}$ was observed in the Akap9-deleted groups (Akap $9^{\mathrm{cko}}$ and $A k a p 9^{\mathrm{K} 0}$ ) compared with WT counterparts. $n=3$ to 5 independent samples for each panel (B); $n=4$ independent samples (C). Scale bar $=100 \mu \mathrm{m}$. 
cells from 60-dpp WT and Akap $9^{\text {cko }}$ mice were analyzed by flow cytometry after propidium iodide staining. During spermatogenesis, spermatogonia $(2 \mathrm{~N}$, diploid) undergo mitotic divisions and differentiate into spermatocytes that enter meiosis I/II to form round haploid spermatids (1N, haploid), which then develop into spermatozoa via spermiogenesis. We found a marked redistribution in cell populations with an increase in the 2N DNA peak (spermatogonia, secondary spermatocytes, and somatic cells, such as Sertoli cells) concomitant with a decrease in the $1 \mathrm{~N}$ peak (haploid spermatids) (Figure 2A), suggesting that germ cells are unable to efficiently complete and exit meiosis I, thus leading to delayed entry into meiosis II to become haploid, round spermatids. In addition, it is also possible that fewer spermatogonia are committed to meiosis due to defects in transforming undifferentiated spermatogonia to spermatocytes to prepare for meiosis I/II.

Germ cell differentiation in day 60 samples was also analyzed by staining tissue cross sections with antibody to JAM-C or PNAG, markers of polarization and the spermatid acrosomal cap, respectively. JAM-C, widely distributed on spermatocytes, concentrates in the anterior of round spermatids and, as spermiogenesis proceeds, polarizes to the junctional plaques in the heads of elongated spermatids ${ }^{32}$ as was also seen in $A k a p 9^{\mathrm{WT}}$ testes sections (Figure 2B). In Akap ${ }^{\text {cko }}$ testes, JAM-C was reduced and abnormally concentrated in spermatocytes. The lack of elongated sper-

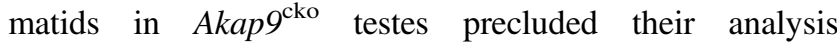
(Figure 2B). A block in differentiation from round to elongated spermatids in Akap $9^{\text {cko }}$ testes was evident by PNAG labeling. PNAG labeled the acrosomal cap in the ES of WT samples and was absent in SC. However, in Akap $9^{\text {cko }}$ samples, PNAG exhibited aberrant cytoplasmic staining in SC (Figure 2B), the significance of which is unclear but may result from a block of further $\mathrm{SC}$ development to generate functional ES.

Next, we evaluated whether the observed impairment in meiosis could be due to abnormalities in the meiotic machinery, such as pairing and synapsis of homologous chromosomes and recombination. The labeling pattern of SYCP3, an essential structural component of the synaptonemal complex involved in the synapsis, recombination, and segregation of meiotic chromosome, was indistinguishable in the WT and Akap $9^{\text {cko }}$ testes (Figure 2B). Next, we examined a marker of DNA double-strand breaks, phosphorylated histone $\gamma-H 2 A X$ present in leptonema to pachynema phases of the first meiotic division. Phosphorylated histone $\gamma-H 2 A X$ densely stains the condensed $X$ and $\mathrm{Y}$ chromosomes that form the sex body as a disruption of the XY body and has been proposed to cause meiotic arrest and male infertility in several mouse strains. ${ }^{33,34}$ The XY body was similar in intensity and distribution in WT and Akap $9^{\text {cko }}$ spermatocytes (Figure 2B). Taken together, these observations suggest that recombination and meiotic chromosome synapsis are cytologically normal in mutant germ cells and that failure of these spermatocytes to progress beyond this stage are probably due to other causes, a conclusion also reached by the study in Akap 9 mutant mice $\left(\right.$ Akap $9^{\text {mei2. }} .5 /$ mei2.5 $)$, which are globally deficient in Akap $9 .{ }^{15}$ Finally, the breeding of Akap $9^{\text {cko }}$ heterozygous males to Akap $9^{\text {cko }}$ homozygous females yielded knockout mice close to the expected mendelian ratio ( $41 \%$, analysis of 183 pups). This finding suggests that AKAP9 is not required for the last stages of spermiation to produce sperm capable of fertilizing the egg. However, the possibility that the AKAP9 protein present in pachytene spermatocytes $(4 \mathrm{~N})$ persists in haploid (1N) spermatids cannot be ruled out.

The absence of obvious defects in meiosis per se in Akap9-deleted animals led us to examine Sertoli cell differentiation, which is necessary to establish a functional $\mathrm{BTB}^{35,36}$ that facilitates the transit of preleptotene spermatocytes from the basal to apical compartments of the seminiferous tubules to complete meiosis I/II. A negative cell cycle regulator, $\mathrm{p} 27^{\mathrm{Kip} 1}$, found in the nuclei of postmitotic Sertoli cells serves as an index of functional maturation. ${ }^{37,38}$ Schimenti et al ${ }^{15}$ detected a reduction in $\mathrm{p} 27^{\mathrm{Kip} 1}$

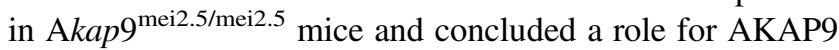
in terminal differentiation of Sertoli cells; however, the analysis was conducted at a single time point, and the age of animals examined was not reported. We evaluated $\mathrm{p} 27^{\mathrm{Kip} 1}$ in $A k a p 9^{\text {cko }}, \operatorname{Akap} 9^{\mathrm{KO}}$, and WT mice at 26 to $30 \mathrm{dpp}$ and 60 dpp. By day 22, functional maturation of Sertoli cells is complete wherein the cells normally cease to divide and establish a BTB. Notably, in day 26 to 30-dpp Akap $9^{\mathrm{WT}}$ and Akap $9^{\mathrm{cko}}$ mice, $\mathrm{p} 27^{\mathrm{Kip} 1}$-stained Sertoli cells lined the basal region of the tubules (Figure $2 \mathrm{C}$ ). Similarly, p2 $7^{\mathrm{Kip} 1}$. positive Sertoli cells were prominent in $\operatorname{Akap} 9^{\mathrm{KO}}$ mice at day 26 (Figure 2C), a time point when gross abnormalities in the seminiferous tubule architecture were already apparent (Figure 1D). Analysis of 60-dpp mice revealed a marked reduction in $\mathrm{p} 27^{\mathrm{Kip} 1}$ staining in the seminiferous tubules of Akap $9^{\text {cko }}$ and Akap $9^{\mathrm{KO}}$ mice compared with WT counterparts (Figure 2C). These data suggest that an alteration in Sertoli maturation in Akap9-deleted testes does not precede the progressive loss of spermatogenesis and reduction in the complexity of cell types within the seminiferous tubules of Akap9-deficient mice. Thus, unlike the conclusions of Schimenti et al ${ }^{15}$ our data indicate that the change in Sertoli maturation is a secondary rather than a primary cause of the observed spermatogenesis defects in Akap9-deficient animals.

\section{Akap9 Deficiency Leads to Alterations in MT Organization That Is Associated with Grossly Normal but Mislocalized F-Actin and BTB Proteins}

To probe whether Akap 9 deletion altered Sertoli cell function, we examined changes in MT and actin distribution and localization of BTB components at different stages of spermatogenesis in $A k a p 9^{\text {cko }}$ and $\mathrm{A} k a p 9^{\mathrm{KO}}$ testes. We first examined the organization of MTs, which are the suspected targets of AKAP9 (Figure 3A), based on published reports 
A
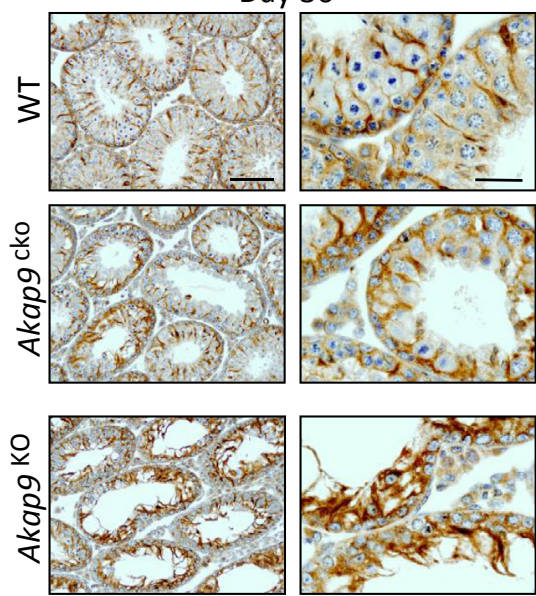

Day 60
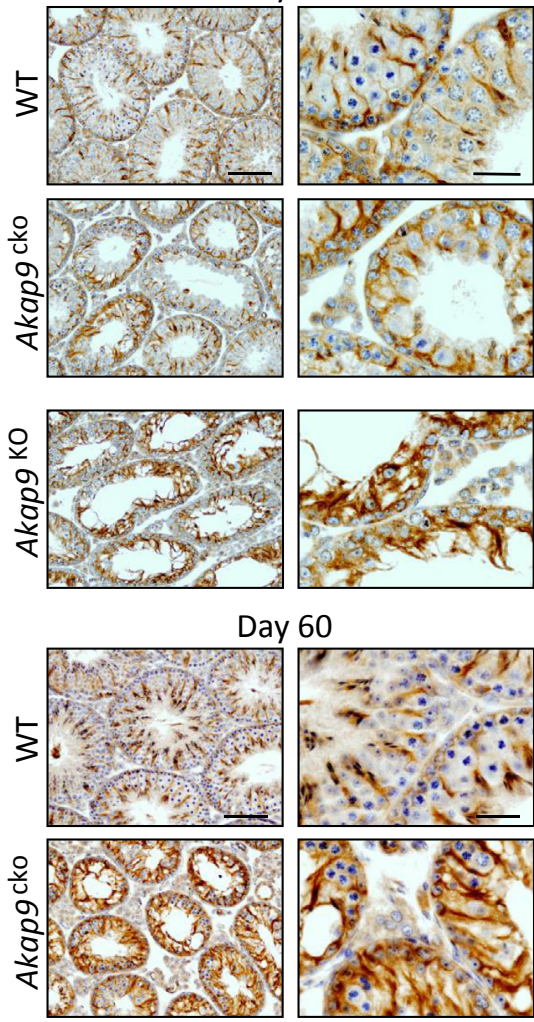

B

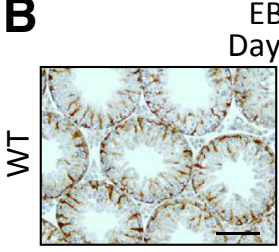

Day 30
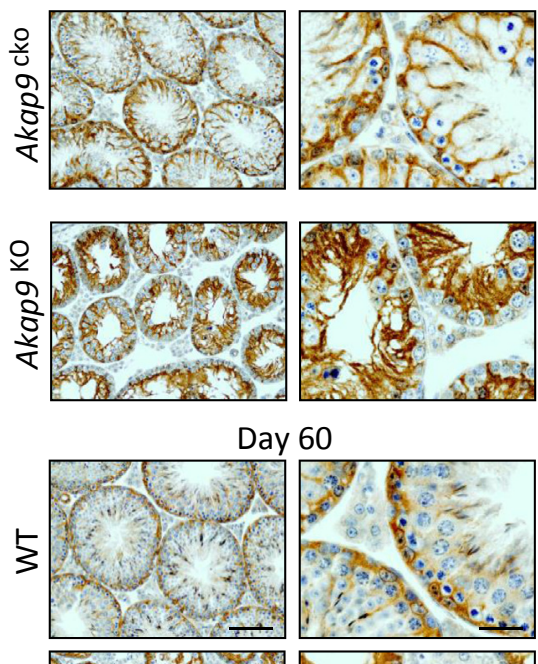

Day 60
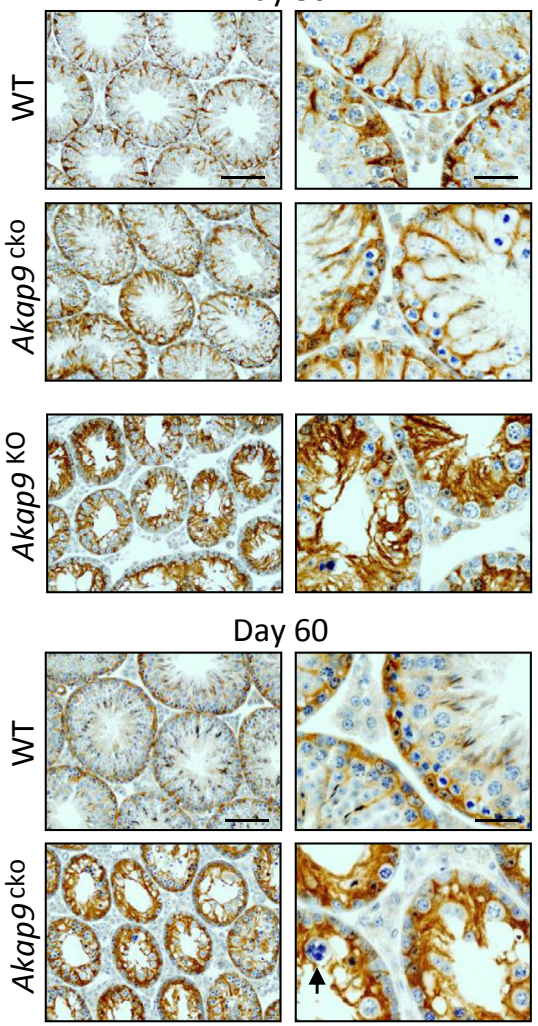
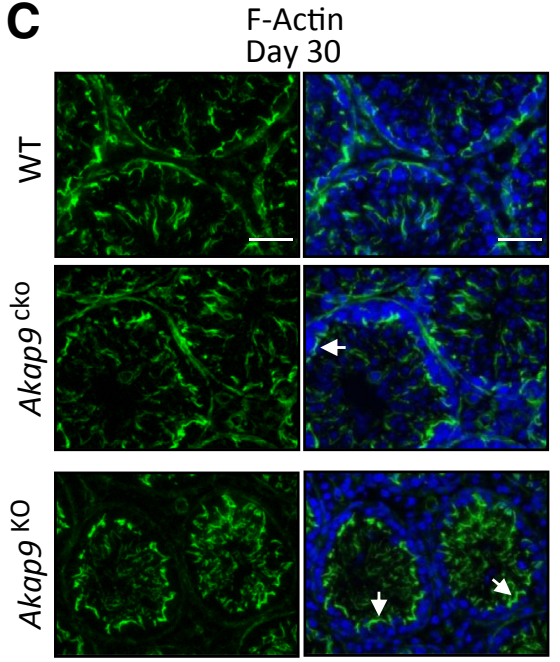

Day 60

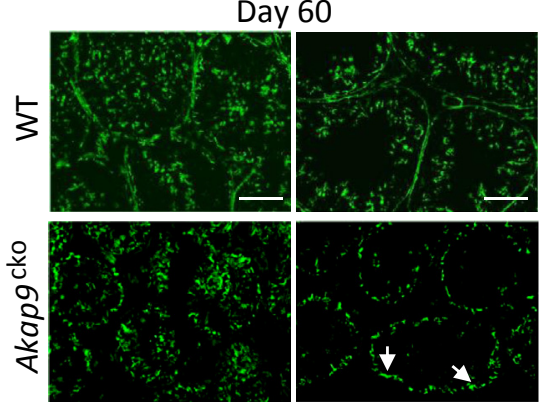

Figure 3 Disruption of the microtubule network but a relatively intact but more apically distributed F-actin cytoskeleton in testes of Akap9-deficient mice. Testes were harvested from wild-type (WT), Akap $9^{\text {cko }}$, and $A k a p 9^{\mathrm{KO}}$ mice at 30 and 60 days post partum. A and B: Analysis of microtubules. Tissue sections were subjected to immunohistologic analysis using antibody to $\beta$-tubulin (A) or EB1 (B), which appear as reddish brown structures in the seminiferous epithelium. Arrow indicates a multinucleated round spermatid in day $60 \mathrm{Akap} 9^{\mathrm{cko}}$, which illustrates degeneration of round spermatids after meiosis in this tubule, a sign that meiosis indeed took place, at least in some tubules, but failed to go beyond round spermatids. C: To assess F-actin distribution, immunofluorescence staining of cross sections with fluorescein isothiocyanate-phalloidin was undertaken, and nuclei were stained with DAPI. Arrows indicate the presence of F-actin that is relatively intact in Akap9-deficient mice but shifted toward the apical aspect of Sertoli and germ cells (DAPI). Representative findings of $n=5$ mice per group. Scale bars: $25 \mu \mathrm{m}$ (A and B, right column; C, Day 30); $100 \mu \mathrm{m}$ (A and B, left column; C, Day 60).

in cell culture systems. ${ }^{7,10,11}$ Because EB1 is a MT plus end-binding protein and a sensitive readout of growing MTs, ${ }^{39}$ we also examined whether there were changes in its localization in mouse testes after Akap9 deletion (Figure 3B). In the age-matched WT control mice at both day 30 and 60 , anti- $\beta$-tubulin-stained MTs appeared as tracks that lay vertically across the basement membrane at almost a $90^{\circ}$ angle from the tunica propria (Figure $3 \mathrm{~A}$ ), where they are known to support the transport of spermatids as they mature during spermiogenesis. ${ }^{2}$ A similar localization was observed for EB1, which is an integral component of the MT-based cytoskeleton (Figure 3B). In Akap $9^{\text {cko }}$ mouse testes, however, $\beta$-tubulin-positive and EB1 -positive MT filaments were misaligned in adult testes by day 60 and lay almost parallel to the tunica propria (Figure 3, A and B). Notably, there was some evidence of these changes in Sertoli cell MT architecture in Akap $9^{\text {cko }}$ mice even in day 30 animals (Figure 3, A and B). These results were further validated by a study using cultured Sertoli cells that found the presence of EB1 comets at the plus ends of growing MTs in WT cells. In contrast, distinct EB1 comets were significantly reduced in Akap ${ }^{\text {cko }}$ cells (Supplemental Figure S2), suggesting a change in MT growth properties in these cells because EB1 binds to the ends of growing but not pausing or depolymerizing MTs. ${ }^{39}$ These findings support the notion that AKAP9 is crucial to maintain fully functional MTs in the seminiferous epithelium. We next examined changes in the actin organization using FITC-phalloidin. F-actin at the BTB of the seminiferous epithelium of $A k a p 9^{\text {cko }}$ and $A k a p 9^{\mathrm{KO}}$ mutant testes in both age groups (day 30 and 60) was not grossly different from the age-matched WT control testes (Figure 3C). However, it was more apically localized and did not extend into the adluminal compartment due to the virtual absence of elongating and elongated spermatids (Figure 3C).

To determine potential effects of Akap9 deletion on TJs, we examined the localization of the TJ-associated protein complex ZO-1 and JAM-A at the BTB in the seminiferous epithelium of $A k a p 9^{\text {cko }}$ and $A k a p 9^{\mathrm{KO}}$ versus the age-matched WT control testes. In control testes, both ZO-1 and JAM-A 

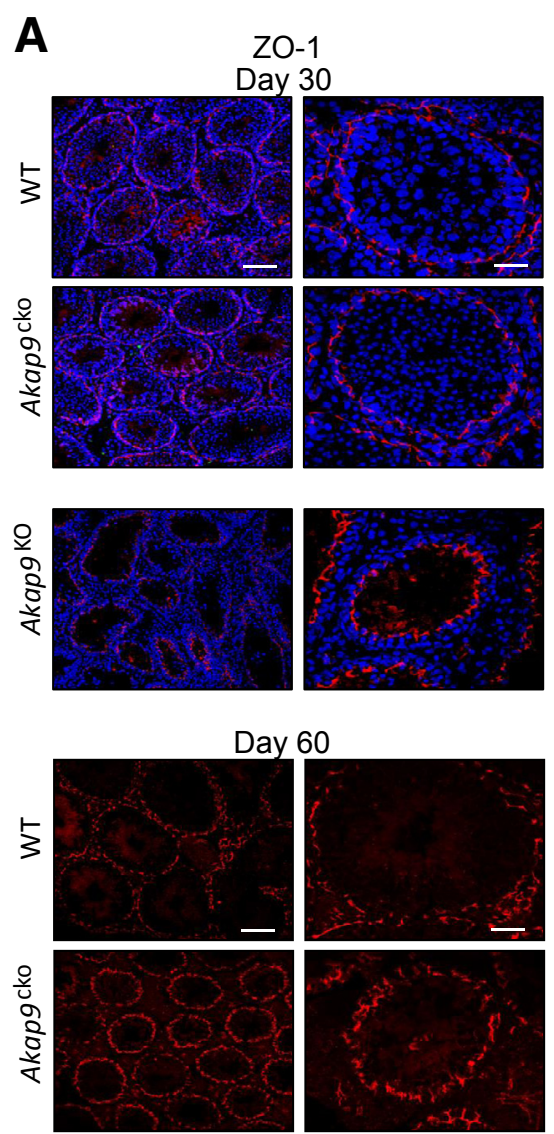

B
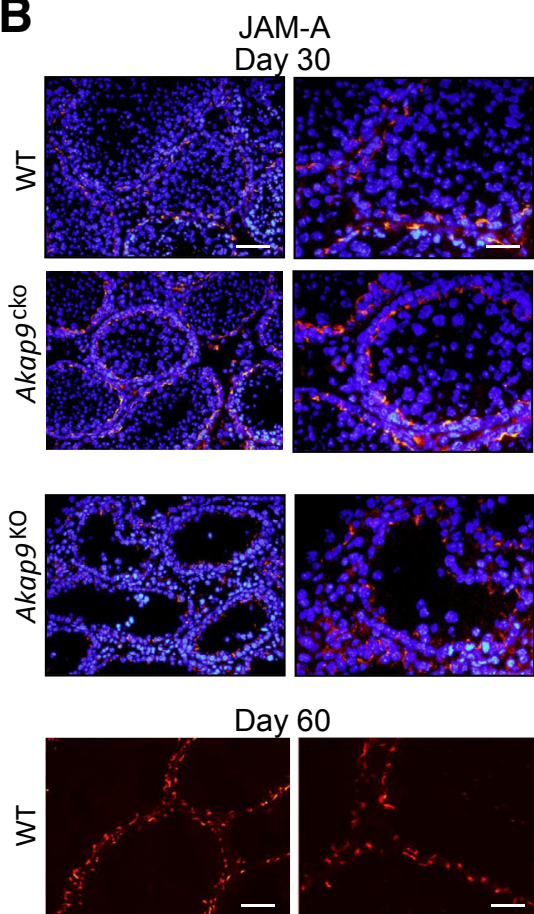

Day 60

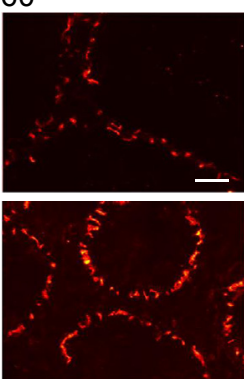

Figure 4 Akapg deletion results in mislocalization of blood-testis barrier (BTB) proteins. A and B: Testes were harvested from wild-type (WT), Akap $9^{\text {cko }}$, and $A k a p 9^{\mathrm{KO}}$ mice at 30 and 60 days post partum, and antibodies for tight junction proteins Z0-1 (an adaptor protein) (A) and JAM-A (an integral membrane protein) (B) were used on cross sections to visualize the localization of these proteins. Redistribution of Z0-1 (A) and JAM-A (B) toward the apical aspect of the seminiferous tubules was observed in Akap9-deleted $\left(\right.$ Akap $\left.^{\mathrm{KO}}, \operatorname{Akap}^{\mathrm{cko}}\right)$ compared with WT samples. Sections were counterstained with DAPI. Representative findings of $n=5$ mice per group. Scale bars: $20 \mu \mathrm{m}$ (B, right column); $25 \mu \mathrm{m}$ (A, right column); $75 \mu \mathrm{m}$ (B, left column); 100 $\mu \mathrm{m}$ (A, left column). were confined to the base of seminiferous tubules, consistent with their localization at the basolateral tight junctions proximal to the basement membrane, a pattern also evident at day 60 (Figure 4). However, in $A k a p 9^{\mathrm{KO}}$ and $A k a p 9^{\text {cko }}$ testes, the BTB proteins no longer restrictively localized near the basement membrane and were uniformly more apical and in some cases (ZO-1, in Akap $9^{\text {cko }}$ testes) localized more vertical or perpendicular to the basement membrane. Notably, a milder but clear phenotype in Akap $9^{\mathrm{cko}}$ mice at $30 \mathrm{dpp}$ significantly progressed by $60 \mathrm{dpp}$ (Figure 4). Next, we examined the GJ-integral membrane protein Connexin 43 (Cx43), found abundantly at the BTB and known to control TJ dynamics ${ }^{40,41}$ and spermatogenesis. ${ }^{42} \mathrm{Cx} 43$ localized to the BTB near the basement membrane of seminiferous tubules and around spermatogonia in both day 30 and 60 WT testes (Figure 5). However, in day 30 Akap $^{\mathrm{KO}}$ testes, it shifted toward the apical surface of Sertoli cells with little localization at the basal side of germ cells. Cx43 also exhibited greater penetration into the adluminal compartment compared with WT counterparts. Notably, in Akap $9^{\text {cko }}$ testes samples, Cx43 increasingly mislocalized from 30 to $60 \mathrm{dpp}$. The more apical localization of ZO-1 and $\mathrm{Cx} 43$ observed in 60-dpp Akap9-deficient mice was similar to that reported in Akap $9^{\text {mei2.5/mei2.5 }}$ mutant animals. ${ }^{15}$ The robust staining of Cx43 in the Akap9-deficient testes compared with the corresponding age-matched WT testes may be the result of tubule shrinkage (Figure 5).
Collectively, these observations suggest that a disruption of MTs in the seminiferous epithelium of the Akap9-deficient testis does not grossly disrupt F-actin and BTB proteins but leads to their shift from a predominantly basal to a more adluminal localization relative to germ cells residing along the basement membrane. The consequences of the shift in Factin and BTB proteins on BTB functionality cannot be predicted because it has been reported that the localization and/or expression of TJ proteins can change over the cycle of the seminiferous epithelium but permeability to the small molecule biotin is still restricted as far as the organized TJ immunoreactivity. ${ }^{43}$ The shift, at least for F-actin, is likely not an indirect consequence of germ cell loss because the subcellular distribution of F-actin and intermediate filaments (vimentin) at the BTB is not markedly affected in $\mathrm{W} / \mathrm{W}^{\mathrm{v}}$ mice, which also lack spermatogenic cells. ${ }^{44,45}$

\section{AKAP9 Is Essential for BTB Function}

To determine whether AKAP9 deletion affects the integrity of the BTB, the impact of global or conditional Akap9 deficiency on BTB permeability was evaluated. We evaluated permeability to molecules of two different sizes using a novel IVM approach to detect permeability to the macromolecule FITC-conjugated inulin (2 to $5000 \mathrm{Da}$, and a conventional biotin tracer (443 to $666 \mathrm{Da})^{46}$ to detect leakage to smaller molecules across the barrier. 

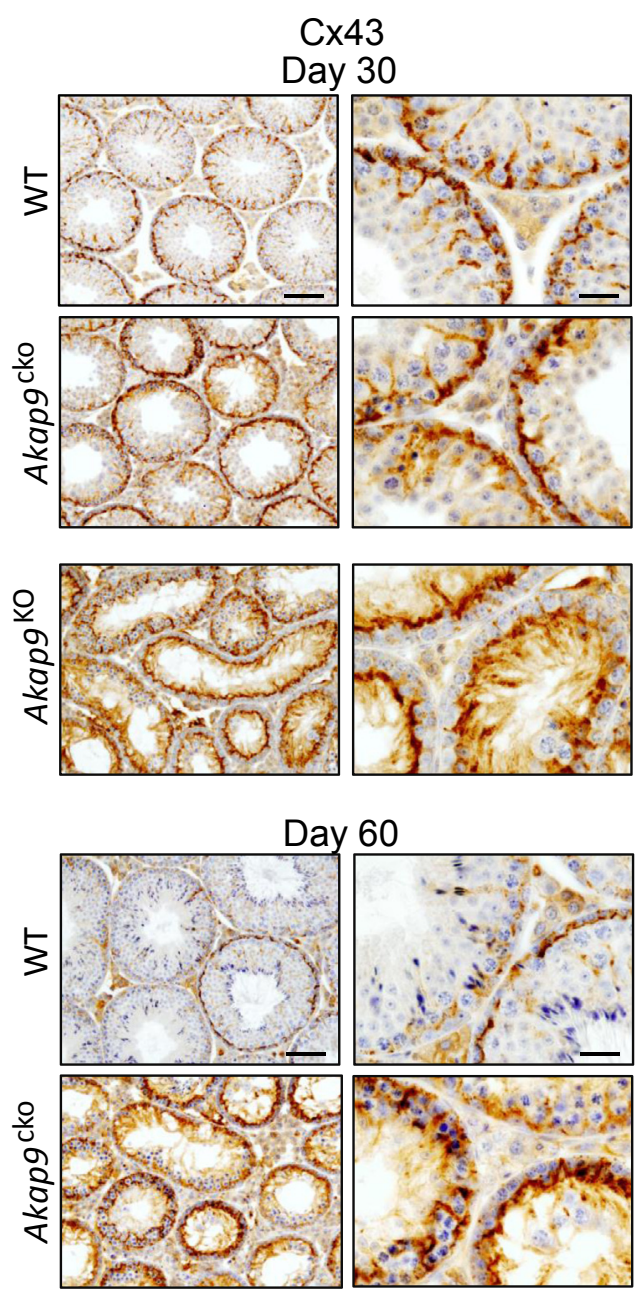

Figure 5 Redistribution of gap junction protein $\mathrm{C} \times 43$. Testes were harvested from wild-type (WT), Akap $9^{\mathrm{cko}}$, and $A k a p 9^{\mathrm{K} 0}$ mice at 30 and 60 days post partum, and tissue sections were stained with anti-Cx43 antibody. In Akap $9^{\mathrm{WT}}$ testes, $\mathrm{C} \times 43$ was tightly restricted to the basal compartment near the basement membrane, consistent with its localization at the BTB. In contrast, in $A k a p g^{\text {cko }}$ and $A k a p g^{\mathrm{K} 0}$ mice the $\mathrm{C} \times 43$ redistributed more to the apical compartment. Representative findings of $n=5$ mice per group. Scale bars: $20 \mu \mathrm{m}$ (right column); $75 \mu \mathrm{m}$ (left column).

For IVM, the permeation of i.v. administered FITC-inulin across the seminiferous epithelial barrier into the adluminal compartment was examined in real time after exteriorization of the testes of anesthetized WT, Akap $9^{\mathrm{KO}}$, and Akap $9^{\mathrm{cko}}$ mice and frank leakage (Figure 6A) versus patchy deposits (Figure 6B) in the adluminal space were assessed. In day 22 animals, FITC-inulin was restricted to the vasculature of WT mice, whereas it accumulated in the lumen within 10 minutes of its i.v. injection (Figure 6A) in a significant fraction of the seminiferous tubules of $A k a p 9^{\mathrm{KO}}$ mice (Figure 6B). A similar analysis was undertaken in day 28 Akap $9^{\text {cko }}$ mice. Frank leakage, as observed in $A k a p 9^{\mathrm{KO}}$ mice, was not present in these $\operatorname{Akap} 9^{\text {cko }}$ animals (data not shown). However, the mice exhibited a significant number of patchy FITC-inulin deposits within the tubules that further increased in 42-dpp animals (Figure 6C), indicating a breach of the BTB. The patchy distribution is similar to that observed by traditional analysis of FITC-inulin in tissue cross sections ${ }^{47,48}$ whereas the more uniform FITC-inulin staining observed in the Akap $9^{\mathrm{KO}}$ (Figure 6A) may be due to more robust leakage in these animals. Unlike the histologic analysis of FITC-inulin, the IVM approach may be able to distinguish between different levels of leakiness because there is no loss of the diffusible FITCinulin during sectioning and tissue preparation and because IVM permits observation of greater tissue volume than tissue sections. The observed difference in extent of leakage between $A k a p 9^{\text {cko }}$ and $A k a p 9^{\mathrm{KO}}$ testes may reflect the deletion of Akap 9 after versus before the BTB is initially established, respectively, thus leading to a greater disruption of the barrier in the latter case. Alternatively, VE-cadherin tTA/tetO-Cre is expected to delete $A k a p 9$ only in differentiating and elongated spermatids in a complete epithelial cycle, ${ }^{19}$ whereas Akap 9 global deletion may lead to deficits in germ cell populations at several stages of spermatogenesis that may contribute to the more severe phenotype. Unexpectedly, the analysis of older $A k a p 9^{\mathrm{KO}}$ and $A k a p 9^{\mathrm{cko}}$ mice revealed a significant reduction in BTB permeability. The 60-day-old Akap $9^{\mathrm{KO}}$ animals no longer had frank leakage but exhibited a patchy distribution (data not shown), and the 90-day-old Akap $9^{\mathrm{KO}}$ and Akap $9^{\text {cko }}$ had a complete reversal of permeability (Figure 6C), indicating a resealing of the BTB to FITC-inulin.

The conventional biotin tracer technique was used to evaluate permeability to a smaller-molecular-weight tracer than FITC-inulin and to assess BTB function across an entire testis cross section. Biotin tracer was injected into the interstitial space of the testes of live anesthetized Akap $9^{\mathrm{KO}}$ mice. Thirty minutes after injection, mice were euthanized, histologic cross sections were prepared from their testes, and the extent of biotin tracer permeation into the seminiferous tubule was determined. In 25- and 90day-old adult WT mice, biotin tracer was present in the interstitial spaces and basal compartment but excluded from the adluminal compartment of the seminiferous tubules (Figure 6D). In contrast, in similarly aged Akap $9^{\mathrm{KO}}$ mice, the biotin tracer significantly accumulated in the adluminal compartment (Figure 6D), indicating permeability at the BTB. However, in day 150 Akap $9^{\mathrm{KO}}$ animals a marked reduction in tracer leakage into the adluminal compartment was observed, which suggested a reversal of the barrier permeability (Figure 6D). Thus, two independent methods of BTB detection indicate initial loss of BTB integrity in Akap9-deficient animals that is increasingly restored in older animals. Notably, the BTB in day 90 Akap $9^{\mathrm{KO}}$ animals is permeable to the smaller biotin tracer (Figure 6D) but blocks the movement of the larger FITCinulin (Figure 6C). This finding suggests that at day 90, the BTB in $A k a p 9^{\mathrm{KO}}$ is in the early stages of resealing and thus blocks entrance of larger molecules, such as FITCinulin, but is still permeable to smaller molecules, such as biotin. As the resealing proceeds, as is the case at day 150 Akap $9^{\mathrm{KO}}$, the permeation of the biotin tracer into the adluminal compartment is also significantly restricted (Figure 6D). 
A
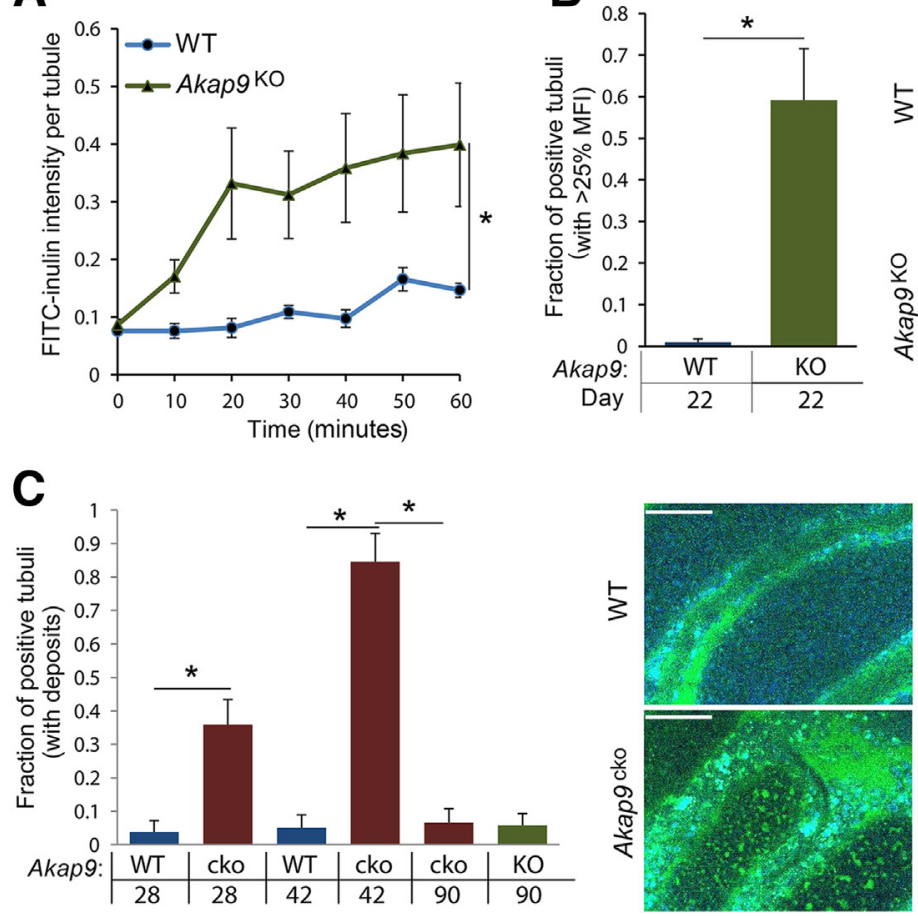

D
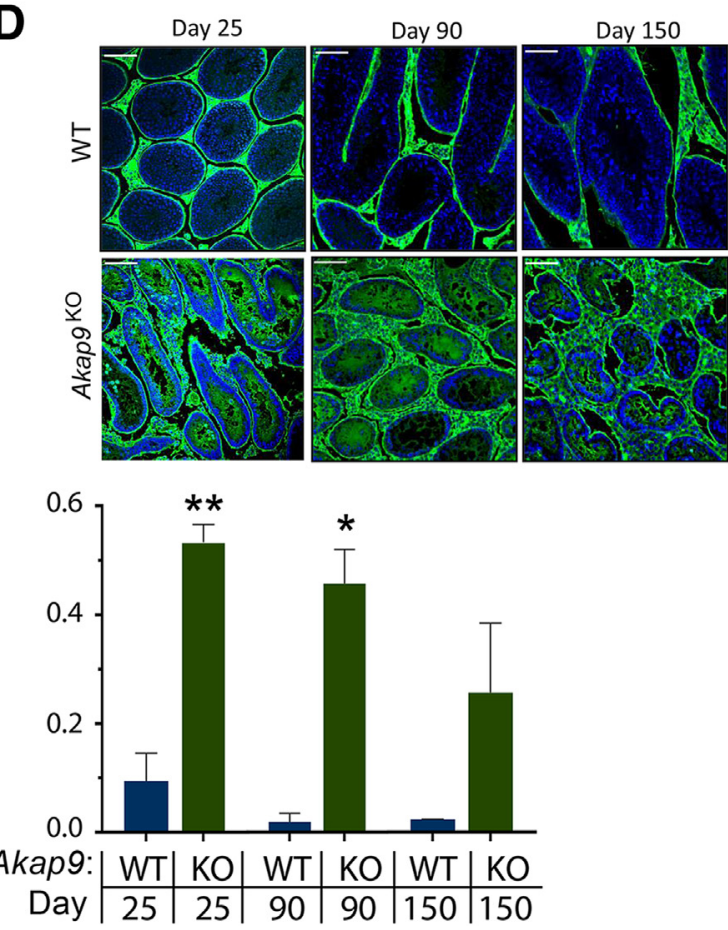

\section{BTB Resealing Is Associated with Resumption of Meiosis and a Reduction in Germ Cell Apoptosis but Continued Defects in Spermiogenesis}

The significant reversal of BTB permeability in 150-dpp Akap $9^{\mathrm{KO}}$ testes led us to examine spermatogenesis in these and even older animals. Histologic cross sections of 150 and 250-dpp $A k a p 9^{\mathrm{KO}}$ mice revealed a significantly larger number of pachytene spermatocytes and round spermatids

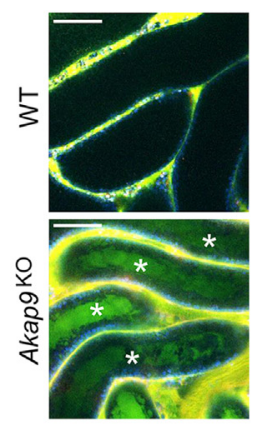

Figure 6 Compromised blood-testis barrier in Akap9-deleted mice to fluorescein isothiocyanate (FITC)-inulin and biotin tracer. A-C: $A k a p 9^{\mathrm{KO}}$ [knockout (KO)], Akap $9^{\text {cko }}$ [conditional knockout (cko)], and $A k a p g^{\text {cko }}$ [wild-type (WT)] control mice were injected i.v with FITC-inulin, and the testes of anesthetized mice were exteriorized and examined by multiphoton intravital microscopy. A: Mean ratio of FITC fluorescence (fluorescence within the lumen of a seminiferous tubule as a fraction of the mean fluorescence in the interstitium) over time in KO compared with control mice at postnatal day 22. Data were statistically evaluated with a repeated-measures analysis of variance with the indicated statistical significance (asterisk) indicting that both groups behave differently over time. B: Quantitative comparison of tubuli with fluorescence (tubulus/interstitum) $>25 \%$ at $60 \mathrm{mi}-$ nutes after FITC-inulin injection in KO and WT mice at indicated postnatal ages of mice. A statistically significant cutoff of $25 \%$ was mathematically determined using a double SD width over control, which yielded a value of $24.8 \%$. Representative images of central accumulation of FITC-inulin (green) in $\mathrm{K} 0$ versus WT mice at the 60 minutes time point are shown. White asterisks indicate positive tubules. C: Quantitative analysis of tubuli presenting with patchy deposits of FITC-inulin in the sustentacular cell area in WT, cko, and KO at indicated postnatal ages of mice. Presented is the fraction of tubuli with deposits over all imaged tubuli. Representative images of WT and cko mice are shown. D: Mice were given an intratesticular injection of biotin tracer, and testes were collected after 30 minutes and processed. Representative images of seminiferous tubules showing restriction of the biotin tracer to the interstitial space and basal compartment of 25-, 90-, and 150-day-old WT mice and free leakage of biotin into the adluminal compartment of day 25 and $90 \mathrm{Akapg}^{\mathrm{KO}}$. In day 150 $A k a p g^{\mathrm{KO}}$ tubules, leakage is reduced significantly. Intratubular fluorescence was quantitated and results are graphed. Biotin intensity refers to the mean ratio of fluorescence of streptavidin (used to detect biotin) within the lumen of a seminiferous tubule as a fraction of the mean fluorescence in the interstitium. $n=5$ to 6 mice per group (A); $n=3$ to 6 (B); $n=3$ to 4 (C); $n=3$ (D). ${ }^{*} P<0.05$, ${ }^{* * P}<0.005$. Scale bar $=100 \mu \mathrm{m}(\mathbf{B}-\mathbf{D})$. Error bars represent SEM. MFI, mean fluorescence intensity. 
A

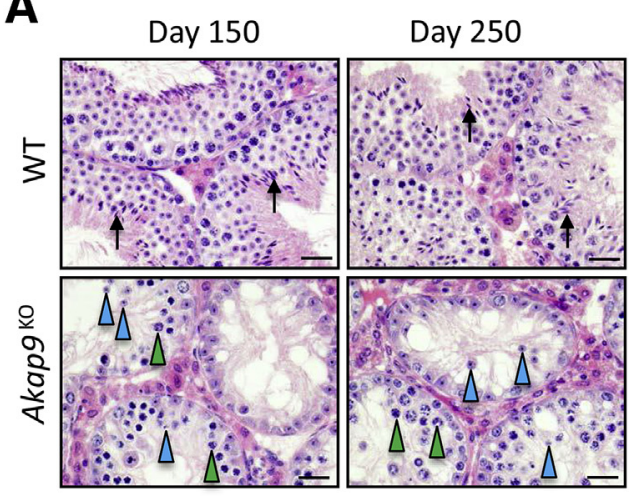

B
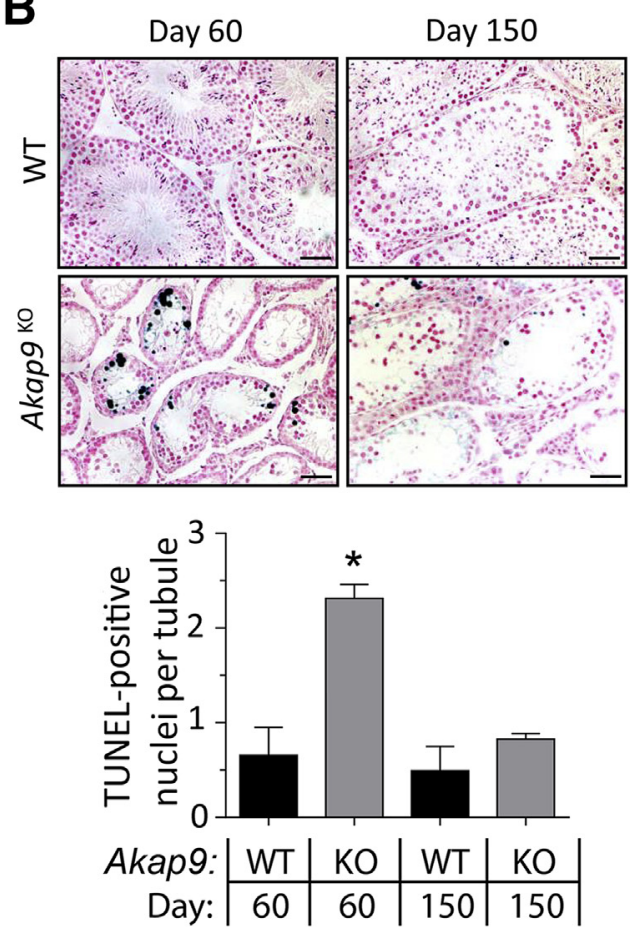

Figure 7 Greater meiosis and resumption of spermatogenesis in older Akap9-deficient mice. A: Examination of meiosis in hematoxylin and eosinstained cross sections of testes from day 150 and 250 Akap $^{\mathrm{KO}}$ and age-matched Akap $9^{\text {WT }}$ [wild-type (WT)] mice reveals the presence of a number of pachytene spermatocytes (green arrowheads) and round spermatids (blue arrowheads). However, elongating spermatids (black arrows) were present only in WT mice. B: Analysis of germ cell apoptosis. Day $60 \operatorname{Akap}^{\mathrm{K} 0}$ seminiferous tubules exhibit significant loss of germ cells and a marked increase in terminal deoxynucleotidyl transferase-mediated dUTP nick-end labeling (TUNEL) - positive cells compared with WT tubules, whereas day 150 Akap $^{\mathrm{KO}}$ animals have much fewer TUNELpositive cells compared with day $60 A k a p g^{\mathrm{K} 0}$ samples. A quantitation of the results from WT and $A k a p g^{\mathrm{K} 0}$ [knockout (KO)] animals of indicated ages is shown. Scale bars: $25 \mu \mathrm{m}$ (A); $50 \mu \mathrm{m}$ (B). ${ }^{\star} P<0.05$. Error bars represent SEM.

spermatids, no elongating/elongated spermatids were observed in the seminiferous epithelium, indicating that spermiogenesis remained completely defective.

\section{Discussion}

AKAPs have been documented in developing germ cells to promote spermiogenesis and the motility of mature sperm by compartmentalization of signaling events. ${ }^{49,50}$ Mice with deletion of AKAP110, 220, 80, 82, or TAKAP80 are all subfertile as a result of reduced sperm motility. ${ }^{5}$ Our work indicates that AKAP9 is not required for germ cell differentiation per se but is essential for both the cyclical restructuring of the BTB required for spermatogenesis and for the germ cell transport that occurs during spermiogenesis. Two lines of evidence suggest that a primary defect in the BTB of Akap9-deleted Sertoli cells leads to impeded progression of germ cells through meiosis I/II and/or fewer spermatogonia committing to meiosis. First, consistent with the reported epithelial cycle stage-specific activity of the VE-cadherin promoter, ${ }^{19}$ we observed selective expression of the Crerecombinase in the Sertoli cells and haploid spermatids but not germ cells of VE-cadtTA/tetO-Cre mice, which predicts permanent deletion of Akap9 in Sertoli cells at puberty but cyclical deletion of Akap 9 in postmeiotic haploid spermatids. Thus, observed defects in germ cells are likely secondary to AKAP9-dependent alterations in BTB in Sertoli cells. Second, the loss and then resealing of the Sertoli cell barrier in Akap9-deficient animals appears to directly correlate with the incidence of spermatogenesis. Notably, the more severe perturbation of BTB function in younger 25 to 27-dpp Akap $9^{\mathrm{KO}}$ versus Akap $9^{\text {cko }}$ may reflect additional roles for AKAP9 in other cell types and/or its deletion in Sertoli cells before the BTB is initially established. Within the Akap $9^{\text {cko }}$ population, the lower penetrance of the phenotype in younger versus older animals may reflect the need for repeated epithelial cycles for efficient Akap9 deletion in Sertoli cells; Cre recombination frequency is likely diminished in Sertoli cells at puberty because these cells are terminally differentiated and thus cease dividing at this time.

The apical and the basal ES (BTB) undergo extensive restructuring during the epithelial cycle of spermatogenesis to facilitate the transport of immotile germ cells across the seminiferous epithelium. This remodeling relies on the actinand MT-based cytoskeleton, the regulation of which is only beginning to be elucidated. Actin microfilament bundles abundant at the apical ES facilitate Sertoli cell-spermatid adhesion and, at the basal ES, support cell adhesion between Sertoli cells, conferring the unusual adhesive strength of the BTB. At stage VIII of the epithelial cycle, these bundles are replaced by branched actin, which remodel these adhesive structures by promoting endocytic vesicle-mediated protein trafficking, signaling, and recycling. These events at the basal and apical ES facilitate BTB restructuring and spermiation, respectively, and are regulated by actin regulatory proteins and members of the Rho family of GTPases. ${ }^{1}$ MTs, on the other hand, are polarized cytoskeletal elements that lie adjacent to the F-actin network and serve as tracks to assist in the transport of endocytic vesicles, organelles, and germ cells, in particular preleptotene spermatocytes or spermatids across the BTB or apical compartment, respectively, during the epithelial cycle., ${ }^{2,3}$ Our data suggest that AKAP9 regulation of MTs may be essential for these functions. End-binding 
proteins (+TIPs), such as EB1, interact with the plus ends of growing MTs, capture MTs at cortical sites to establish an asymmetric MT network, and regulate MT linkage to actin. ${ }^{12,51}$ In epithelial cells, $\beta$-catenin at adherens junctions binds MT end-binding proteins to facilitate the delivery of junctional components, ${ }^{52}$ which would be critical for BTB restructuring. EB1-decorated MTs were disorganized in Sertoli cells of the seminiferous tubules of AKAP9-deficient testes, and cultured Akap $9^{\text {cko }}$ Sertoli cells lacked distinct EB1 comets, which in other cell systems reflect a change in MT dynamics. ${ }^{39}$ In AKAP9-silenced endothelial cells, a similar reduction in localization of EB1 comets at MT plus ends was associated with impairment of the instantaneous MT growth rate, a reduction of the MT growth length, and an inability to increase barrier functions after activation of Epac 1/2.

AKAP9 is a large $450-\mathrm{kDa}$ scaffold protein that binds PKA $^{6}$ and Epac1 ${ }^{53}$ and in Sertoli cells was found to bind the cyclic nucleotide phosphodiesterase PDE4D3, which may locally titrate cAMP levels in the centrosome. ${ }^{54} \mathrm{~A}$ deficiency in some of these cAMP-responsive binding partners results in male infertility attributed to defects in sperm motility ${ }^{55}$ or germ-Sertoli cell interactions, ${ }^{19}$ whereas in other cases, male fertility is unaffected. ${ }^{56-58}$ Thus, although cAMP is one of the most important secondary messengers controlling spermiogenesis, ${ }^{5}$ a deletion of cAMP-responsive pathways potentially modulated by AKAP9 does not recapitulate the BTB defects observed in our knockout mice. Therefore, it is possible that AKAP9 may be recruited by or affect cAMP-independent pathways to modulate the restructuring of the BTB. Moreover, AKAP9 also recruits a number of proteins involved in signal transduction. ${ }^{54,59-61}$ Thus, we cannot rule out additional roles for AKAP9 beyond the modulation of the MT cytoskeleton in regulating Sertoli-BTB function.

The BTB is composed of three types of intercellular junctions: cadherin-based adherens junction called basal ES restricted between adjacent Sertoli cells near the basement membrane, occludin containing TJs, and connexin-based GJs that all interact to form the BTB. ${ }^{1}$ Tightly packed F-actin filament bundles at the ES together with junctional molecules facilitate BTB remodeling required for germ cell transport to the adluminal compartment. ${ }^{62-64}$ Deletion of components of TJ structures at the BTB in mice leads to infertility. For example, males deficient in occludin or claudin 11 lack TJs but are viable. Mice with claudin deficiency have tubules with aggregates of Sertoli cells, and occludin knockouts, with age, exhibit a Sertoli cell-only phenotype in seminiferous tubules. ${ }^{65} \mathrm{ZO}-1$ is a putative adaptor for occludin, claudins, and JAM-A at the BTB. ${ }^{66}$ The impact of its deletion on the testis is not known because ZO-1 knockouts are embryonic lethal, ${ }^{67,68}$ but the deletion of ZO-2 (a close sibling of ZO-1) in the testis leads to subfertility with a concomitant disruption of the BTB. ${ }^{69}$ Deletion of the GJ component Cx43 selectively in Sertoli cells results in spermatogenesis arrest associated with a decrease in spermatogonia and an increase in the number of Sertoli cells per tubule in which spermatocytes failed to develop beyond type B. ${ }^{42,70}$ These phenotypes have similarities with the gross spermatogenesis phenotypes observed in Akap9-deficient animals. However, in the absence of AKAP9, F-actin filaments and BTB components continue to concentrate at the BTB but exhibit a shift toward the apical surface of the seminiferous epithelium with weak or no localization along the basement membrane. Although the consequences of apically localized Factin and TJ proteins to BTB function is not clear, it is possible that in addition to being mislocalized, components of the junctions may not be functioning normally. For example, disrupted cross talk between MTs and Cx43 containing GJs may impede the polarized delivery of GJ components to the membrane needed for BTB remodeling. ${ }^{71}$ In turn, $\mathrm{Cx} 43$ binding to tubulin may potentially aid in anchoring and stabilizing MTs at GJs. ${ }^{72}$ Together, the significance of our findings is that a deletion of Akap9 leads to a disorganization of the MT network in the seminiferous tubules, which is associated with marked alterations in BTB integrity despite relatively normal, albeit more apical F-actin and TJ protein distribution.

An unexpected restriction of permeability across the BTB was observed in older Akap9-deficient mice by as yet unknown mechanisms. BTB restoration after its disassembly or disruption leads to a resumption of spermatogenesis in published studies. ${ }^{35,73,74}$ However, the increasing reversal of BTB permeability in adult Akap9-deficient mice did not lead to normal levels of spermatogenesis. This may be due to residual permeability or a resealed barrier that is largely dysfunctional. Indeed, the loss of Sertoli cell expression of a negative cell cycle regulator, $\mathrm{p} 27^{\mathrm{Kip} 1}$ in older (60 dpp) Akap9deficient animals despite evidence of the resealing of the barrier at this age, suggests that Sertoli cells may have entered a transitional state, exhibiting features of undifferentiated and differentiated Sertoli cells that does not support dynamic BTB restructuring. Finally, despite the greater resumption of spermatogenesis (larger numbers of pachytene spermatocytes and round spermatids) in older Akap9-deficient animals, the absence of elongated/elongating spermatids indicates a complete lack of restoration of spermiogenesis, which may be due to a requirement for AKAP9-regulated MTs in transport of the adluminal round spermatids ${ }^{75,76}$ and/or in MT-based morphologic changes in the spermatid head and elongation of the tail that occurs during spermiogenesis. ${ }^{2}$

In summary, the deletion of AKAP9 after establishment of the BTB has resulted in insights into the regulatory role of this MT-guiding protein in BTB restructuring and reveals fundamental roles for this protein and, by extension, the MT network in this process and subsequent spermiogenesis.

\section{Acknowledgments}

We thank Drs. Michel Bornens (CNRS-Institut CURIE, Paris, France), Michel Aurrand-Lions (Inserm, Marseille, France), and Shigeyoshi Itohara (RIKEN Institute, Saitama, Japan) for anti-AKAP9 antibody, JAM-C antibody, and CAG-flp on a C57Bl/6J mouse strain, respectively. 


\section{Supplemental Data}

Supplemental material for this article can be found at http://dx.doi.org/10.1016/j.ajpath.2015.10.007.

\section{References}

1. Cheng CY, Mruk DD: The blood-testis barrier and its implications for male contraception. Pharmacol Rev 2012, 64:16-64

2. Tang EI, Mruk DD, Cheng CY: MAP/microtubule affinity-regulating kinases, microtubule dynamics, and spermatogenesis. J Endocrinol 2013, 217:R13-R23

3. O'Donnell L, O'Bryan MK: Microtubules and spermatogenesis. Semin Cell Dev Biol 2014, 30:45-54

4. Pidoux G, Tasken K: Specificity and spatial dynamics of protein kinase A signaling organized by A-kinase-anchoring proteins. J Mol Endocrinol 2010, 44:271-284

5. Tasken K, Aandahl EM: Localized effects of cAMP mediated by distinct routes of protein kinase A. Physiol Rev 2004, 84: $137-167$

6. Wong W, Scott JD: AKAP signalling complexes: focal points in space and time. Nat Rev Mol Cell Biol 2004, 5:959-970

7. Sehrawat S, Ernandez T, Cullere X, Takahashi M, Ono Y, Komarova Y, Mayadas TN: AKAP9 regulation of microtubule dynamics promotes Epac1-induced endothelial barrier properties. Blood 2011, 117:708-718

8. Lin JW, Wyszynski M, Madhavan R, Sealock R, Kim JU, Sheng M: Yotiao, a novel protein of neuromuscular junction and brain that interacts with specific splice variants of NMDA receptor subunit NR1. J Neurosci 1998, 18:2017-2027

9. Chen L, Kass RS: A-kinase anchoring protein 9 and IKs channel regulation. J Cardiovasc Pharmacol 2011, 58:459-513

10. Rivero S, Cardenas J, Bornens M, Rios RM: Microtubule nucleation at the cis-side of the Golgi apparatus requires AKAP450 and GM130. EMBO J 2009, 28:1016-1028

11. Larocca MC, Jin M, Goldenring JR: AKAP350 modulates microtubule dynamics. Eur J Cell Biol 2006, 85:611-619

12. Jiang $\mathrm{K}$, Akhmanova A: Microtubule tip-interacting proteins: a view from both ends. Curr Opin Cell Biol 2011, 23:94-101

13. Oldenburger A, Poppinga WJ, Kos F, de Bruin HG, Rijks WF, Heijink IH, Timens W, Meurs H, Maarsingh H, Schmidt M: A-kinase anchoring proteins contribute to loss of E-cadherin and bronchial epithelial barrier by cigarette smoke. Am J Physiol Cell Physiol 2014, 306:C585-C597

14. Robles-Valero J, Martin-Cofreces NB, Lamana A, Macdonald S, Volkov Y, Sanchez-Madrid F: Integrin and CD3/TCR activation are regulated by the scaffold protein AKAP450. Blood 2010, 115: 4174-4184

15. Schimenti KJ, Feuer SK, Griffin LB, Graham NR, Bovet CA, Hartford S, Pendola J, Lessard C, Schimenti JC, Ward JO: AKAP9 is essential for spermatogenesis and sertoli cell maturation in mice. Genetics 2013, 194:447-457

16. Byers S, Graham R, Dai HN, Hoxter B: Development of Sertoli cell junctional specializations and the distribution of the tight-junctionassociated protein ZO-1 in the mouse testis. Am J Anat 1991, 191:35-47

17. Dejana E, Orsenigo F, Lampugnani MG: The role of adherens junctions and VE-cadherin in the control of vascular permeability. J Cell Sci 2008, 121:2115-2122

18. Lu N, Sargent KM, Clopton DT, Pohlmeier WE, Brauer VM, McFee RM, Weber JS, Ferrara N, Silversides DW, Cupp AS: Loss of vascular endothelial growth factor A (VEGFA) isoforms in the testes of male mice causes subfertility, reduces sperm numbers, and alters expression of genes that regulate undifferentiated spermatogonia. Endocrinology 2013, 154:4790-4802
19. Aivatiadou E, Mattei E, Ceriani M, Tilia L, Berruti G: Impaired fertility and spermiogenetic disorders with loss of cell adhesion in male mice expressing an interfering Rap1 mutant. Mol Biol Cell 2007, 18:1530-1542

20. Kanki H, Suzuki H, Itohara S: High-efficiency CAG-FLPe deleter mice in C57BL/6J background. Exp Anim 2006, 55:137-141

21. Sun JF, Phung T, Shiojima I, Felske T, Upalakalin JN, Feng D, Kornaga T, Dor T, Dvorak AM, Walsh K, Benjamin LE: Microvascular patterning is controlled by fine-tuning the Akt signal. Proc Natl Acad Sci U S A 2005, 102:128-133

22. Keryer G, Di Fiore B, Celati C, Lechtreck KF, Mogensen M, Delouvee A, Lavia P, Bornens M, Tassin AM: Part of Ran is associated with AKAP450 at the centrosome: involvement in microtubule-organizing activity. Mol Biol Cell 2003, 14:4260-4271

23. Zhang C, Yeh S, Chen YT, Wu CC, Chuang KH, Lin HY, Wang RS, Chang YJ, Mendis-Handagama C, Hu L, Lardy H, Chang C: Oligozoospermia with normal fertility in male mice lacking the androgen receptor in testis peritubular myoid cells. Proc Natl Acad Sci U S A 2006, 103:17718-17723

24. Xiao X, Cheng CY, Mruk DD: Intercellular adhesion molecule-1 is a regulator of blood-testis barrier function. J Cell Sci 2012, 125:5677-5689

25. Mruk DD, Cheng CY: An in vitro system to study Sertoli cell bloodtestis barrier dynamics. Methods Mol Biol 2011, 763:237-252

26. Li JC, Lee TW, Mruk TD, Cheng CY: Regulation of Sertoli cell myotubularin (rMTM) expression by germ cells in vitro. J Androl 2001, 22:266-277

27. Aravindan GR, Pineau CP, Bardin CW, Cheng CY: Ability of trypsin in mimicking germ cell factors that affect Sertoli cell secretory function. J Cell Physiol 1996, 168:123-133

28. Stokol T, O’Donnell P, Xiao L, Knight S, Stavrakis G, Botto M, von Andrian UH, Mayadas TN: C1q governs deposition of circulating immune complexes and leukocyte Fcgamma receptors mediate subsequent neutrophil recruitment. J Exp Med 2004, 200:835-846

29. Schneider CA, Rasband WS, Eliceiri KW: NIH Image to ImageJ: 25 years of image analysis. Nat Methods 2012, 9:671-675

30. Meng J, Holdcraft RW, Shima JE, Griswold MD, Braun RE: Androgens regulate the permeability of the blood-testis barrier. Proc Natl Acad Sci U S A 2005, 102:16696-16700

31. Tanaka H, Pereira LA, Nozaki M, Tsuchida J, Sawada K, Mori H, Nishimune Y: A germ cell-specific nuclear antigen recognized by a monoclonal antibody raised against mouse testicular germ cells. Int J Androl 1997, 20:361-366

32. Gliki G, Ebnet K, Aurrand-Lions M, Imhof BA, Adams RH: Spermatid differentiation requires the assembly of a cell polarity complex downstream of junctional adhesion molecule-C. Nature 2004, 431:320-324

33. Cloutier JM, Turner JM: Meiotic sex chromosome inactivation. Curr Biol 2010, 20:R962-R963

34. Royo H, Polikiewicz G, Mahadevaiah SK, Prosser H, Mitchell M, Bradley A, de Rooij DG, Burgoyne PS, Turner JM: Evidence that meiotic sex chromosome inactivation is essential for male fertility. Curr Biol 2010, 20:2117-2123

35. Toyama Y, Ohkawa M, Oku R, Maekawa M, Yuasa S: Neonatally administered diethylstilbestrol retards the development of the bloodtestis barrier in the rat. J Androl 2001, 22:413-423

36. Russell LD, Bartke A, Goh JC: Postnatal development of the Sertoli cell barrier, tubular lumen, and cytoskeleton of Sertoli and myoid cells in the rat, and their relationship to tubular fluid secretion and flow. Am J Anat 1989, 184:179-189

37. Beumer TL, Kiyokawa H, Roepers-Gajadien HL, van den Bos LA, Lock TM, Gademan IS, Rutgers DH, Koff A, de Rooij DG: Regulatory role of p27kip1 in the mouse and human testis. Endocrinology 1999, 140:1834-1840

38. Cipriano SC, Chen L, Burns KH, Koff A, Matzuk MM: Inhibin and p27 interact to regulate gonadal tumorigenesis. Mol Endocrinol 2001, 15:985-996

39. Morrison EE, Wardleworth BN, Askham JM, Markham AF, Meredith DM: EB1, a protein which interacts with the APC tumour 
suppressor, is associated with the microtubule cytoskeleton throughout the cell cycle. Oncogene 1998, 17:3471-3477

40. Carette D, Weider K, Gilleron J, Giese S, Dompierre J, Bergmann M, Brehm R, Denizot JP, Segretain D, Pointis G: Major involvement of connexin 43 in seminiferous epithelial junction dynamics and male fertility. Dev Biol 2010, 346:54-67

41. Li MW, Mruk DD, Lee WM, Cheng CY: Connexin 43 is critical to maintain the homeostasis of the blood-testis barrier via its effects on tight junction reassembly. Proc Natl Acad Sci U S A 2010, 107:17998-18003

42. Brehm R, Zeiler M, Ruttinger C, Herde K, Kibschull M, Winterhager E, Willecke K, Guillou F, Lecureuil C, Steger K, Konrad L, Biermann K, Failing K, Bergmann M: A sertoli cellspecific knockout of connexin43 prevents initiation of spermatogenesis. Am J Pathol 2007, 171:19-31

43. Tarulli GA, Meachem SJ, Schlatt S, Stanton PG: Regulation of testicular tight junctions by gonadotrophins in the adult Djungarian hamster in vivo. Reproduction 2008, 135:867-877

44. Terada N, Ohno N, Yamakawa H, Baba T, Fujii Y, Zea Z, Ohara O, Ohno S: Immunohistochemical study of protein $4.1 \mathrm{~B}$ in the normal and W/W(v) mouse seminiferous epithelium. J Histochem Cytochem 2004, 52:769-777

45. Kurohmaru M, Kanai Y, Hayashi Y: A cytological and cytoskeletal comparison of Sertoli cells without germ cell and those with germ cells using the W/WV mutant mouse. Tissue Cell 1992, 24:895-903

46. Ding L, Zhang Y, Tatum R, Chen YH: Detection of tight junction barrier function in vivo by biotin. Methods Mol Biol 2011, 762:91-100

47. Xiao X, Mruk DD, Tang EI, Massarwa R, Mok KW, Li N, Wong CK, Lee WM, Snapper SB, Shilo BZ, Schejter ED, Cheng CY: N-wasp is required for structural integrity of the blood-testis barrier. PLoS Genet 2014, 10:e1004447

48. Paul C, Robaire B: Impaired function of the blood-testis barrier during aging is preceded by a decline in cell adhesion proteins and GTPases. PLoS One 2013, 8:e84354

49. Luconi M, Cantini G, Baldi E, Forti G: Role of a-kinase anchoring proteins (AKAPs) in reproduction. Front Biosci (Landmark Ed) 2011, 16:1315-1330

50. Moss SB, Gerton GL: A-kinase anchor proteins in endocrine systems and reproduction. Trends Endocrinol Metab 2001, 12:434-440

51. Tamura N, Draviam VM: Microtubule plus-ends within a mitotic cell are 'moving platforms' with anchoring, signalling and force-coupling roles. Open Biol 2012, 2:120132

52. Stehbens SJ, Akhmanova A, Yap AS: Microtubules and cadherins: a neglected partnership. Front Biosci (Landmark Ed) 2009, 14: 3159-3167

53. Sehrawat S, Cullere X, Patel S, Italiano J Jr, Mayadas TN: Role of Epac1, an exchange factor for Rap GTPases, in endothelial microtubule dynamics and barrier function. Mol Biol Cell 2008, 19:1261-1270

54. Tasken KA, Collas P, Kemmner WA, Witczak O, Conti M, Tasken K: Phosphodiesterase 4D and protein kinase a type II constitute a signaling unit in the centrosomal area. J Biol Chem 2001, 276:21999-22002

55. Skalhegg BS, Huang Y, Su T, Idzerda RL, McKnight GS, Burton KA: Mutation of the Calpha subunit of PKA leads to growth retardation and sperm dysfunction. Mol Endocrinol 2002, 16:630-639

56. Jin SL, Richard FJ, Kuo WP, D'Ercole AJ, Conti M: Impaired growth and fertility of cAMP-specific phosphodiesterase PDE4Ddeficient mice. Proc Natl Acad Sci U S A 1999, 96: 11998-12003

57. Burton KA, Treash-Osio B, Muller CH, Dunphy EL, McKnight GS: Deletion of type IIalpha regulatory subunit delocalizes protein kinase A in mouse sperm without affecting motility or fertilization. J Biol Chem 1999, 274:24131-24136
58. Pereira L, Cheng H, Lao DH, Na L, van Oort RJ, Brown JH, Wehrens XH, Chen J, Bers DM: Epac2 mediates cardiac beta1adrenergic-dependent sarcoplasmic reticulum $\mathrm{Ca} 2+$ leak and arrhythmia. Circulation 2013, 127:913-922

59. Takahashi M, Mukai H, Oishi K, Isagawa T, Ono Y: Association of immature hypophosphorylated protein kinase cepsilon with an anchoring protein CG-NAP. J Biol Chem 2000, 275:34592-34596

60. Takahashi M, Shibata H, Shimakawa M, Miyamoto M, Mukai H, Ono Y: Characterization of a novel giant scaffolding protein, CGNAP, that anchors multiple signaling enzymes to centrosome and the golgi apparatus. J Biol Chem 1999, 274:17267-17274

61. Gillingham AK, Munro S: The PACT domain, a conserved centrosomal targeting motif in the coiled-coil proteins AKAP450 and pericentrin. EMBO Rep 2000, 1:524-529

62. Li SY, Mruk DD, Cheng CY: Focal adhesion kinase is a regulator of F-actin dynamics: new insights from studies in the testis. Spermatogenesis 2013, 3:e25385

63. Vogl AW, Du M, Wang XY, Young JS: Novel clathrin/actin-based endocytic machinery associated with junction turnover in the seminiferous epithelium. Semin Cell Dev Biol 2014, 30:55-64

64. Su W, Mruk DD, Cheng CY: Regulation of actin dynamics and protein trafficking during spermatogenesis-insights into a complex process. Crit Rev Biochem Mol Biol 2013, 48:153-172

65. Morrow CM, Mruk D, Cheng CY, Hess RA: Claudin and occludin expression and function in the seminiferous epithelium. Philos Trans R Soc Lond B Biol Sci 2010, 365:1679-1696

66. Cheng CY, Mruk DD: Cell junction dynamics in the testis: Sertoligerm cell interactions and male contraceptive development. Physiol Rev 2002, 82:825-874

67. Katsuno T, Umeda K, Matsui T, Hata M, Tamura A, Itoh M, Takeuchi K, Fujimori T, Nabeshima Y, Noda T, Tsukita S, Tsukita S: Deficiency of zonula occludens-1 causes embryonic lethal phenotype associated with defected yolk sac angiogenesis and apoptosis of embryonic cells. Mol Biol Cell 2008, 19:2465-2475

68. Wang H, Ding T, Brown N, Yamamoto Y, Prince LS, Reese J, Paria BC: Zonula occludens-1 (ZO-1) is involved in morula to blastocyst transformation in the mouse. Dev Biol 2008, 318:112-125

69. Xu J, Anuar F, Ali SM, Ng MY, Phua DCY, Hunziker W: Zona occludens-2 is critical for blood-testis barrier integrity and male fertility. Mol Biol Cell 2009, 20:4268-4277

70. Sridharan S, Simon L, Meling DD, Cyr DG, Gutstein DE, Fishman GI, Guillou F, Cooke PS: Proliferation of adult sertoli cells following conditional knockout of the Gap junctional protein GJA1 (connexin 43) in mice. Biol Reprod 2007, 76:804-812

71. Shaw RM, Fay AJ, Puthenveedu MA, von Zastrow M, Jan YN, Jan LY; Microtubule plus-end-tracking proteins target gap junctions directly from the cell interior to adherens junctions. Cell 2007, 128:547-560

72. Giepmans BN, Verlaan I, Moolenaar WH: Connexin-43 interactions with ZO-1 and alpha- and beta-tubulin. Cell Commun Adhes 2001, 8: 219-223

73. Su L, Cheng CY, Mruk DD: Adjudin-mediated Sertoli-germ cell junction disassembly affects Sertoli cell barrier function in vitro and in vivo. Int J Biochem Cell Biol 2010, 42:1864-1875

74. Mok KW, Mruk DD, Lee WM, Cheng CY: Spermatogonial stem cells alone are not sufficient to re-initiate spermatogenesis in the rat testis following adjudin-induced infertility. Int J Androl 2012, 35:86-101

75. Vogl AW, Vaid KS, Guttman JA: The Sertoli cell cytoskeleton. Adv Exp Med Biol 2008, 636:186-211

76. Guttman JA, Kimel GH, Vogl AW: Dynein and plus-end microtubule-dependent motors are associated with specialized Sertoli cell junction plaques (ectoplasmic specializations). J Cell Sci 2000, 113(Pt 12):2167-2176 